\title{
Diet High in Soybean Oil Increases Susceptibility to Colitis in Mice
}

Poonamjot Deol ${ }^{1,2}$, Paul Reugger ${ }^{2}$, Geoff Logan ${ }^{2}$, Ali Shawki ${ }^{3}$, Jiang Li ${ }^{3}$, Jon Mitchell ${ }^{2}$, Jacqueline $\mathrm{Yu}^{1}{ }^{1}$, Varadh Piamthai ${ }^{2}$, Sarah H. Radi ${ }^{1}$, John Newman ${ }^{4}$, Oliver Fiehn ${ }^{4}$, Declan McCole $^{3}$, Meera Nair ${ }^{3}$, Ansel Hsiao ${ }^{2}$, James Borneman ${ }^{2}$ and Frances M. Sladek ${ }^{*} 1$

${ }^{1}$ Department of Molecular, Cell and Systems Biology, University of California, Riverside;

${ }^{2}$ Department of Microbiology and Plant Pathology, University of California, Riverside ;

${ }^{3}$ Division of Biomedical Sciences, University of California, Riverside; ${ }^{4}$ National Institutes of Health West Coast Metabolomics Center, University of California, Davis

*Corresponding authors: P. Deol (pdeol001@ucr.edu), F.M. Sladek (sladek@ucr.edu) 
Diet High in Soybean Oil Increases Susceptibility to Colitis in Mice

\section{SUMMARY}

Soybean oil (SO), the most prevalent cooking oil in the United States, consists primarily of linoleic acid (LA, C18:2 omega-6), a polyunsaturated fatty acid positively linked to the development of ulcerative colitis (UC) in humans. Here, we show that dietary SO increases intestinal epithelial barrier permeability and susceptibility to colitis in mice. It also disrupts the balance of isoforms encoded by the UC susceptibility gene Hepatocyte Nuclear Factor $4 \alpha$ (HNF4 $\alpha$ ), which in turn impacts barrier function and IBD susceptibility. The SO diet causes gut dysbiosis, including an increased abundance of an adherent, invasive Escherichia coli (AIEC) which can use LA as a carbon source. Metabolomic analysis indicates that gut bacteria and the SO diet can alter levels of LA and its oxylipin and endocannabinoid metabolites in the gut. Our results suggest that an SOenriched diet increases susceptibility to colitis due to effects on intestinal HNF4 $\alpha$, microbiota and LA metabolites. 


\section{Diet High in Soybean Oil Increases Susceptibility to Colitis in Mice}

\section{INTRODUCTION}

Inflammatory bowel disease (IBD) is a multifactorial disorder, the pathogenesis of which can be influenced by host genetics, immune dysfunction, intestinal microbiota and a variety of environmental factors, including diet (Knight-Sepulveda et al., 2015). Over the last century there has been a shift in the composition of the American diet with soybean oil (SO) being the component that has increased the most (Blasbalg et al., 2011). Soybean oil is currently the most highly consumed cooking oil in the U.S. and its consumption is growing worldwide (USDA Economic Research Service, 2020). Importantly, the increase in soybean oil consumption since the 1970s (Blasbalg et al., 2011) parallels the increased incidence of IBD in the U.S. (Molodecky et al., 2012). While the major fatty acid present in soybean oil, linoleic acid (LA, C18:2 $\omega 6$ ), has been positively linked to the development of ulcerative colitis (UC) (Tjonneland et al., 2009; Wood, 2010), there are conflicting reports on whether soybean oil promotes or protects against IBD (Barros et al., 2010; Moldal et al., 2014; Rashvand et al., 2015; Wiese et al., 2016). Additionally, LA, and its downstream metabolite arachidonic acid (AA, C20:4, 66 ), are precursors to bioactive lipids such as oxylipins and endocannabinoids (Alvheim et al., 2013; Gabbs et al., 2015). A diet high in LA could thus lead to altered levels of oxylipins, endocannabinoids which have been linked to IBD (Cani et al., 2016; Diab et al., 2019; Zhang et al., 2013).

LA is the endogenous ligand for HNF4 $\alpha$ (Yuan et al., 2009), an IBD susceptibility gene (UK IBD Genetics Consortium et al., 2009) and a member of the nuclear receptor superfamily of ligand-dependent transcription factors (Sladek et al., 1990). The human and mouse $H N F 4 A$ genes are highly conserved and contain two promoters (P1 and P2) that drive the expression of P1 isoforms (HNF4a1-6) and P2 isoforms (HNF4 $\alpha 7-12)$ which have distinct first exons (Ko et al., 2019). While the whole-body knock-out of HNF4 $\alpha$ is an embryonic lethal (Chen et al., 1994), 


\section{Diet High in Soybean Oil Increases Susceptibility to Colitis in Mice}

exon-swap mice that express either only P1- or only P2-derived HNF4 $\alpha$ (Briancon and Weiss, 2006) can be used to study the role of HNF4 $\alpha$ isoforms in various tissues, including the intestines. Both HNF4 $\alpha$ promoters are active in the small intestines and colon, albeit in different parts of the crypt: P1-HNF4 $\alpha$ is expressed in the differentiated portion at the top of the colonic crypt and P2HNF4 $\alpha$ in the proliferative compartment in the bottom half of the crypt (Chellappa et al., 2016). While both $\alpha 1 \mathrm{HMZ}$ (only P1-HNF4 $\alpha$ ) and $\alpha 7 \mathrm{HMZ}$ (only P2-HNF4 $\alpha$ ) exon-swap mice are healthy under unstressed conditions, we have shown previously that on a low fat, high-fiber diet, $\alpha 1 \mathrm{HMZ}$ males are resistant while $\alpha 7 \mathrm{HMZ}$ males are susceptible to developing dextran sulfate sodium (DSS)-induced colitis (Chellappa et al., 2016).

Intestinal microbiota play an important role in the regulation of gut homeostasis and perturbation in the gut microbiome composition (dysbiosis) can lead to intestinal inflammation and various intestinal pathologies, including IBD (Buttó and Haller, 2016; Ohno, 2015; Tamboli et al., 2004). Notably, increased incidence of the adherent, invasive Escherichia coli (AIEC) has been reported in patients with IBD (Darfeuille-Michaud et al., 2004; Palmela et al., 2018), and a Western diet (high in animal fat and sugar) leads to increased intestinal AIEC colonization in genetically susceptible mice (Martinez-Medina et al., 2014). We recently isolated a novel mouse AIEC (mAIEC) with 90\% DNA sequence homology to the human AIEC and showed that it can cause colitis and exacerbate intestinal inflammation in mice (Shawki et al., 2020).

We have previously shown that a diet enriched in soybean oil similar to the current American diet can shorten intestinal colonic crypt length (Deol et al., 2015) and that oxylipin metabolites of LA and alpha-linolenic acid (ALA, C18-3, (13) in the liver positively correlate with SO-induced obesity in mice (Deol et al., 2017). While previous studies have demonstrated the role of diet, especially the widely used Western diet, in IBD pathogenesis (Hintze et al., 2018; Marion- 


\section{Diet High in Soybean Oil Increases Susceptibility to Colitis in Mice}

Letellier et al., 2016), the effect of the most commonly used cooking oil in the U.S. -- soybean oil -- has not been examined.

In this study, we determined the impact of soybean oil on the development of IBD using a diet that mimics the standard American diet in terms of total fat and LA content. In three different mouse models of IBD -- dextran-sodium sulfate (DSS)-induced, IL10 knockout mice and HNF4 $\alpha$ expon swap mice -- we observed increased susceptibility to IBD in adult males fed the soybean oil diet. We examined potential underlying mechanisms including the effect of the diet on HNF4 $\alpha$ protein levels as well as the gut microbiome and both host and bacterial metabolomes. Our results show that while dietary soybean oil, by itself, does not lead to IBD, it does decrease intestinal epithelial barrier function, which could contribute to increased susceptibility to colitis. We show a disruption of the balance between HNF4 $\alpha$ isoform levels and an expansion of mAIEC in the intestines of SO-fed mice which could also promote susceptibility to colitis. Finally, metabolomic analysis of both host intestinal cells and gut bacteria implicates elevated levels of LA oxylipins and reduced levels of endocannabinoids and the omega-3 eicosapentaenoic acid (EPA) in IBD susceptibility. Taken together, our results indicate that an SO-enriched diet, analogous to the current American diet, may be a predisposing environmental factor in the development of colitis and that intestinal barrier dysfunction, HNF4 $\alpha$ isoform imbalance, dysbiosis and metabolomic perturbations may contribute to this effect.

\section{METHODS}

\section{Animals and diets}

Care and treatment of animals was in accordance with guidelines from and approved by the University of California, Riverside Institutional Animal Care and Use Committee and followed 


\section{Diet High in Soybean Oil Increases Susceptibility to Colitis in Mice}

NIH guidelines. The animals were maintained on a 12:12 hours light-dark cycle in either a conventional, non-specific-pathogen free vivarium or in a gnotobiotic facility. Conventionally raised, male wild-type (WT) C57B16/N (Charles River), exon swap HNF4 $\alpha$ ( $\alpha 1 \mathrm{HMZ)} \mathrm{(Briancon}$ and Weiss, 2006) and IL-10//- mice (Kühn et al., 1993) (Jackson Labs, Stock\#: 002251) were used in the study. The IL-10 $10^{-/}$mice were in the B6 strain, which is known to develop the more mild form of spontaneous colitis (JAX Labs, catalog \# 002251). Germ-free mice (C57B1/6,Taconic) were raised under gnotobiotic conditions, as described previously (Alavi et al., 2020) and fed either a standard, autoclavable low-fat mouse chow (LabDiet 5K52) or a soybean oil-based high fat diet, with $(\mathrm{SO}+\mathrm{f})$ or without added fiber (SO), for up to 24 weeks (both high fat diets have $35 \mathrm{kcal} \%$ fat, and 18.6 and $19 \mathrm{kcal} \%$ LA, respectively; see Supplementary Table 1 for detailed composition of diets). All mice had ad libitum access to food and water (other than the indicated fasting times). All the mice used in this study were young, adult males. At the end of the study, mice were euthanized by carbon dioxide inhalation, in accordance with NIH guidelines.

\section{Dextran sulfate sodium (DSS) treatment}

WT or $\alpha 1 \mathrm{HMZ}$ mice that had been on the diets for 8 to 15 weeks were treated with $2.5 \%$ dextran sodium sulfate salt (DSS) (reagent grade, MW 3.6-5 kDa, MP Biomedicals, \#160110, Santa Ana, CA) in water ad libitum for six days and sacrificed immediately or allowed to recover up to 3 days with tap water. Mice were continued on the same diet before, during and after DSS treatment and monitored daily for changes in body weight, stool consistency, ruffled fur and activity level. Presence of blood in the stool was checked every other day using Hemoccult Dispensapak Plus (catalog no. 61130, Beckman Coulter). 


\section{Diet High in Soybean Oil Increases Susceptibility to Colitis in Mice}

\section{Tissue collection}

Tissues were collected and snap frozen in liquid nitrogen prior to storage at $-80{ }^{\circ} \mathrm{C}$ for immunoblotting and metabolomic analysis, or fixed in 10\% neutral-buffered formalin for 24 hours before storing in $30 \%$ sucrose plus PBS solution at $4{ }^{\circ} \mathrm{C}$ for subsequent histological analysis. Liver and adipose tissue (mesenteric, perirenal, gonadal and flank subcutaneous) were excised and weighed.

\section{Tissue Embedding, Sectioning and Staining}

The entire large intestine was excised and its length measured. A 1.0 to $1.5-\mathrm{cm}$ piece adjacent to the rectum was cut and fixed in $10 \%$ neutral-buffered formalin as above, embedded in optimal cooling temperature (OCT) compound and sectioned at 5- $\mu \mathrm{m}$ thickness on a Microm Cryostat and stored at $20^{\circ} \mathrm{C}$. All slides were rehydrated in $95 \%$ ethanol for 7 minutes, tap water for 7 minutes, ddH20 for 2 minutes, and stained in hematoxylin (Ricca Chemical) for 40 seconds. Slides were then dipped in tap water for 30 seconds, running tap water for 90 seconds, $95 \%$ ethanol for 15 seconds and subsequently counterstained in eosin (Sigma-Aldrich) for 3 seconds and dipped in $95 \%$ and $100 \%$ ethanol two and three times, respectively, for 20 seconds each time. Slides were left in Citrisolve (Fisher Scientific) for at least 40 seconds. This staining process was completed in succession in a single session. Slides were fixed and preserved with Permount (Fisher Chemicals). Histology images were captured on an Evos Microscope (Life Technologies). Crypt length and submucosal thickness were measured using SPOT Imaging software (Sterling Heights, $\mathrm{MI})$.

\section{Immunoblot Analysis}

Whole cell extracts were prepared from tissues stored in liquid nitrogen and analyzed by immuno chemiluminescence after determination of protein concentration by the Bradford Assay, 


\section{Diet High in Soybean Oil Increases Susceptibility to Colitis in Mice}

as described previously (Chellappa et al., 2016; Maeda et al., 2006). The protein extracts were separated by $10 \%$ sodium dodecyl sulfate-polyacrylamide gel electrophoresis (SDS-PAGE) and transferred to Immobilon membrane (EMD Millipore, Billerica, MA). The membrane was blocked with 5\% nonfat milk for 30 minutes, incubated in primary antibodies (mouse monoclonal antiHNF4 $\alpha$ P1 and P2; catalog no. PP-K9218-00 and PP-H6939-00, respectively, R\&D Systems) in $1 \%$ milk, overnight at $4{ }^{\circ} \mathrm{C}$. After several washes in TBST (Tris-buffered saline, $0.1 \%$ Tween 20 ), the blots were incubated in horseradish peroxidase (HRP)-conjugated goat anti-mouse (GaMHRP) secondary antibody (Jackson ImmunoResearch Laboratories) for 40 minutes at room temperature followed by three 5-minutes washes in TBST and two 5-minute washes in TBS (Trisbuffered saline). Blots were developed using SuperSignal' ${ }^{\mathrm{TM}}$ West Pico PLUS Chemiluminescent Substrate (Thermofisher Scientific) and imaged in a Chemi-Doc imaging system (Bio-Rad). Coomassie staining of blots verified equal protein loading.

The blots that were reprobed for beta-actin (rabbit anti-actin; catalog no. A2066, Sigma) were washed twice in TBST before incubating in a stripping buffer $(0.5 \mathrm{M} \mathrm{NaOH}$ solution $)$ at room temp for 5 minutes with shaking, washed twice with TBST and once with TBS (3 minutes each). Blots were blocked in 5\% milk and the immunoblot procedure described above was followed.

\section{FITC-dextran assay}

Mice were fasted overnight on wood chip bedding (Newco Specialty, catalog \# 91100). After 15 hours, mice were weighed and gavaged with FITC-Dextran (FD-4 Sigma) diluted in water at a dose of $600 \mu \mathrm{g} / \mathrm{gm}$ body weight. The gavage was performed under yellow lights and staggered 2 minutes between animals. Mice were sacrificed 4 hours after gavage and blood was collected via cardiac puncture (BD 3-ml Luer-Lok Syringes, catalog no. 14-823-435, Fisher and BD 26 G 5/8 inch hypodermic needles, catalog no. 14-826-6A, Fisher) into1.5-ml Eppendorf tubes. Samples 


\section{Diet High in Soybean Oil Increases Susceptibility to Colitis in Mice}

were placed on ice for 45 minutes and then spun $9.3 \mathrm{rcf}$ for 15 minutes after which serum was collected into a fresh tube. Samples were loaded into black 96-well plates (Corning, catalog no. 3991) in triplicate, at a dilution of 1:5 in water. Serum FITC-Dextran concentration was determined on a Veritas Microplate Luminometer (Turner Biosystems, Sunnyvale, CA), GloMax software (Promega, Madison, WI), using excitation/emission wavelengths of 490/520 nm (Shawki et al., 2020). The relative fluorescence units obtained for the samples were compared to the values obtained from a standard curve generated by diluting the fluorophore stock in water.

\section{Intestinal immune cell profile}

\section{IEL and LPL isolation}

Intestinal epithelial (IELs) and lamina propria lymphocytes (LPLs) were isolated from mouse small intestines as described previously (Couter and Surana, 2016). Briefly, the entire small intestine was excised and gently flushed with cold PBS and mesenteric fat and Peyer's Patches were carefully removed. The intestine was cut into 3 to 4 -inch segments; each segment was rolled on a paper towel moistened with Gibco RPMI 1640 Media to remove any residual fat tissue. The segments were inverted using curved forceps and placed in $30 \mathrm{ml}$ extraction medium -- RPMI plus $93 \mu 15 \%(\mathrm{w} / \mathrm{v})$ dithiothreitol (DTT), $60 \mu \mathrm{l} 0.5 \mathrm{M}$ EDTA and $500 \mu \mathrm{l}$ fetal bovine serum per small intestine, $\sim 40 \mathrm{~cm}$ long -- and stirred at $500 \mathrm{rpm}$ for 15 minutes at $37^{\circ} \mathrm{C}$. A steel strainer was used to separate tissue pieces from the IEL-rich supernatant, which was placed on ice. Residual mucus from the tissue segments was removed by blotting on a dry paper towel. These fragments were then put in a 1.5-ml Eppendorf tube with $600 \mu 1$ of digestion medium: $25 \mathrm{ml}$ RPMI plus 12.5 mg dispase, $37.5 \mathrm{mg}$ collagenase II and $300 \mu \mathrm{l}$ FBS. Dispase (Gibco, catalog no. 17105041) and collagenase (Gibco, catalog no. 17101015) were added immediately before use. The tissue was minced inside the tube using scissors, put in a cup containing $25 \mathrm{ml}$ of digestion media and stirred 


\section{Diet High in Soybean Oil Increases Susceptibility to Colitis in Mice}

at $500 \mathrm{rpm}$ for 15 minutes. After this, any large chunks of tissue were broken up by pipetting up and down with a serological pipette and stirring at $37{ }^{\circ} \mathrm{C}$ was continued for an additional 15 minutes. Digested tissue and the IEL containing supernatant was then passed through a $100-\mu \mathrm{m}$ cell strainer into a 50-ml tube and the strainer rinsed with $20 \mathrm{ml}$ of RPMI containing 10\% FBS. The filtered solution was centrifuged at $500 \mathrm{x}$ g for 10 minutes at $4^{\circ} \mathrm{C}$; the supernatant was carefully decanted and the pellet resuspended in $1 \mathrm{ml}$ of RPMI containing $10 \% \mathrm{FBS}$. The resuspended cells were filtered through a $40-\mu \mathrm{m}$ cell strainer into a $50-\mathrm{ml}$ tube and the strainer was rinsed with $20 \mathrm{ml}$ of RPMI containing 10\% FBS. The filtered solution was centrifuged at $500 \mathrm{xg}$ for 10 minutes at $4{ }^{\circ} \mathrm{C}$; the supernatant was carefully decanted and the pellet resuspended in $1 \mathrm{ml}$ of RPMI containing 2\% FBS. This suspension was then used for flow cytometry as described below.

\section{PBMC isolation}

Mice were euthanized and blood was collected and immediately mixed with $4 \%$ sodium citrate followed by addition of Histopaq-1077 (catalog no. 45ZW2, Grainger). This mix was centrifuged at $400 \mathrm{~g}$ for 30 minutes at room temperature. PBMCs were carefully aspirated from the interphase and washed with culture medium.

Flow cytometry

Isolated PBMC, IELs and LPLs were washed in fluorescence activated cell sorting buffer (FACS) buffer and then incubated with Fc block $(25 \mu \mathrm{g} / \mathrm{mL} \alpha \mathrm{CD} 16 / 32$ and $10 \mu \mathrm{g} / \mathrm{ml} \mathrm{rat} \mathrm{IGg})$, stained for 30 minutes with flow antibodies: F4/80 (Cl:A3-1, Bio Rad MCA497FB ), SiglecF(E502440, BD Biosciences 562757), CD4 (RM4-5, BD Biosciences 550954), Ly6C (HK 1.4, Biolegend 128018), CD11b (M1/70, Biolegend 101226), CD11c (N418, Biolegend 117310), 


\section{Diet High in Soybean Oil Increases Susceptibility to Colitis in Mice}

Ly6G (1A8, Biolegend 127628), MHCII (M5/114.15.2, Biolegend 107622), CD19 (1D3, BD Biosciences 562956), CD115 (AFS98, Biolehend 135517) and CD8 (53-6.7, Biolegend 100742). All cells were run on the BD LSRII (BD Biosciences) and analyzed on FlowJo (FlowJo ${ }^{\mathrm{TM}}$ v10). Cell populations were identified as: macrophage $\left(\mathrm{CD}_{11 \mathrm{~b}} \mathrm{~F}^{+} / 80^{+}\right)$, eosinophils $\left(\mathrm{CD} 11 \mathrm{~b}^{+} \mathrm{SiglecF}^{+}\right)$, monocytes $\left(\mathrm{CD} 11 \mathrm{~b}^{+} \mathrm{Ly}_{6} \mathrm{C}^{+}\right)$, neutrophils $\left(\mathrm{CD} 11 \mathrm{~b}^{+} \mathrm{Ly}_{6 \mathrm{G}^{+}}\right), \mathrm{CD}^{+} \mathrm{T}$ cells $\left(\mathrm{CD} 4^{+} \mathrm{CD}^{-}\right), \mathrm{CD}^{+} \mathrm{T}$ cells $\left(\mathrm{CD}^{+} \mathrm{CD}^{-}\right)$and $\mathrm{B}$ cells $\left(\mathrm{CD} 4^{-} \mathrm{CD} 19^{+}\right)$.

\section{Isolation of intestinal epithelial cells (IECs) for metabolome and microbiome analysis}

Intestinal epithelial cells (IECs) were isolated for microbiome and metabolomic analysis as previously described (Shawki et al. 2020). Bacterial DNA was isolated from the IECs using the DNeasy PowerSoil Kit (Qiagen, Valencia, CA) with a 30-second bead-beating step using a MiniBeadbeater-16 (BioSpec, Bartlesville, OK). For metabolomics analysis, the cells were flash frozen in liquid nitrogen and stored at $-80^{\circ} \mathrm{C}$ until processing .

\section{Bacterial rRNA internal transcribed spacer (ITS) library construction and sequencing}

Illumina bacterial rRNA ITS gene libraries were constructed as follows: PCRs were performed in an MJ Research PTC-200 thermal cycler (Bio-Rad Inc., Hercules, CA) in 25- $\mu$ l reactions containing $50 \mathrm{mM}$ Tris ( $\mathrm{pH} 8.3$ ), bovine serum albumin (BSA) at $500 \mu \mathrm{g} / \mathrm{ml}, 2.5 \mathrm{mM}$ $\mathrm{MgCl} 2,250 \mu \mathrm{M}$ of each deoxynucleotide triphosphate (dNTP), $400 \mathrm{nM}$ of the forward PCR primer, $200 \mathrm{nM}$ of each reverse PCR primer, $2.5 \mu 1$ of DNA template and 0.625 units JumpStart Taq DNA polymerase (Sigma-Aldrich, St. Louis, MO). PCR primers targeted a portion of the small-subunit (ITS-1507F,GGTGAAGTCGTAACAAGGTA) and large-subunit (ITS-23SR, GGGTTBCCCCATTCRG) rRNA genes and the hypervariable ITS region (Ruegger et al., 2014), with the reverse primers including a 12-bp barcode and both primers including the sequences 


\section{Diet High in Soybean Oil Increases Susceptibility to Colitis in Mice}

needed for Illumina cluster formation; primer binding sites were the reverse and complement of the commonly used small-subunit rRNA gene primer 1492R (Frank et al., 2008) and the largesubunit rRNA gene primer 129F (Hunt et al., 2006). PCR primers were only frozen and thawed once. Thermal cycling parameters were $94{ }^{\circ} \mathrm{C}$ for 5 minutes; 35 cycles of $94{ }^{\circ} \mathrm{C}$ for 20 seconds, $56{ }^{\circ} \mathrm{C}$ for 20 seconds, and $72{ }^{\circ} \mathrm{C}$ for 40 seconds; followed by $72{ }^{\circ} \mathrm{C}$ for 10 minutes. PCR products were purified using a Qiagen QIAquick PCR Purification Kit (Qiagen) according to the manufacturer's instructions. DNA sequencing (single-end 150 base) was performed using an Illumina MiSeq (Illumina, Inc., San Diego, CA).

\section{Bacterial rRNA ITS sequence processing and analysis}

The UPARSE pipeline was used for de-multiplexing, length trimming, quality filtering and amplicon sequence variant (ASV) picking using default parameters or recommended guidelines (Edgar, 2013) updated at https://www.drive5.com/usearch/ manual10/uparse_pipeline.html. Briefly, after demultiplexing and using the recommended 1.0 expected error threshold, sequences were trimmed to a uniform length of $145 \mathrm{bp}$ and then dereplicated. Dereplicated sequences were subjected to error correction (denoised) and chimera filtering to generate zero radius operational taxonomic units (ZOTUs) using UNOISE3 (Edgar, 2016). An ASV table was then generated using the otutab command. ASVs having non-bacterial DNA were identified by performing a local BLAST search (Altschul et al., 1990) of their seed sequences against the nucleotide database. ASVs were removed if any of their highest scoring BLAST hits contained taxonomic IDs within the rodent family, the kingdoms Fungi or Viridiplantae kingdoms, or PhiX. Taxonomic assignments of the bacterial ASVs were made by finding the lowest common taxonomic level of the highest BLAST hits excluding unclassified designations. Data were normalized within each 


\section{Diet High in Soybean Oil Increases Susceptibility to Colitis in Mice}

sample by dividing the number of reads in each ASV by the total number of reads in that sample.

The bacterial rRNA ITS sequences have been deposited in the National Center for Biotechnology Information (NCBI)'s Sequence Read Archive (SRA) under the SRA BioProject Accession PRJNA622821.

\section{Bacterial rRNA ITS sequence analysis}

QIIME (Caporaso et al. 2010) was used to create the abundance tables for the phylotypes at various taxonomic levels. Correlation analyses and plots, as well as bacteria species plots, were performed using Prism (GraphPad, La Jolla, CA).

\section{Isolation of mAIEC}

The mAIEC strain used in this study (UCR-SoS5, referred to as SO mAIEC in the Results) was isolated from subcutaneous fat collected from mice fed the high soybean oil diet $(\mathrm{SO}+\mathrm{f}) \mathrm{using}$ a selective medium, E. coli ChromoSelect Agar B, as described by the manufacturer (SigmaAldrich, St. Louis, MO). The strain was purified by selecting a colony from the selective media and then performing two successive streak plating procedures on LB agar to obtain single colonies. The strain was confirmed to have the identical rRNA ITS nucleotide sequence as the $E$. coli phylotype identified by the Illumina sequence analysis by PCR amplifying the rRNA ITS region of the strain and sequencing the amplicons using the Sanger method.

\section{mAIEC phenotypic tests}

Adherence and invasion ability of mAIEC to $\mathrm{CaCo} 2$ brush border epithelial (CaCo2-BBe) cells was examined using previously described methods (Shawki et al. 2020). Intracellular 


\section{Diet High in Soybean Oil Increases Susceptibility to Colitis in Mice}

replication of mAIEC was performed in J774A.1 cells (ATCC TIB-67), murine macrophages maintained in RPMI plus 10\% FBS, penicillin $(100 \mathrm{U} / \mathrm{ml})$, and streptomycin $(100 \mu \mathrm{g} / \mathrm{ml})$ until the day before the experiment, at which point they were maintained in the same media without antibiotics. Intracellular replication of mAIEC in J774A.1 cells was determined by a gentamicin survival assay using 24-well plates with $2 \mathrm{ml}$ of media per well. J774A.1 monolayers were infected at an MOI of 20 bacteria/macrophage and incubated for 2 hours at $37{ }^{\circ} \mathrm{C}$ with $5 \% \mathrm{CO} 2$. Infected macrophages were then washed twice with PBS and incubated 1 hour in RPMI plus 10\% FBS and $150 \mathrm{mg} / \mathrm{ml}$ gentamicin to kill extracellular bacteria. The J774A.1 cells were washed once with PBS and then lysed by incubation with $1 \mathrm{ml}$ of $1 \%$ Triton-X 100 for 30 minutes; using two extra uninoculated wells, an average J774A.1 cell count per well was obtained at this point. The lysed cell solutions $(1 \mathrm{ml})$ were collected, centrifuged at $14,000 \times \mathrm{g}$ for 10 seconds, the supernatants were decanted, and the cells were resuspended in $120 \mu 1$ PBS. The lysed cell solutions were serially diluted, spread-plated on LB agar, incubated overnight at $37^{\circ} \mathrm{C}$, and the bacteria were enumerated. This process was repeated for another plate but after the 1 -hour $150 \mathrm{mg} / \mathrm{ml}$ gentamycin incubation described above, the cells were washed once with PBS, and then RPMI plus $10 \%$ FBS and 20 $\mathrm{mg} / \mathrm{ml}$ gentamicin was added and the cells were allowed to incubate for another 23 hours at $37^{\circ} \mathrm{C}$. Intracellular replication of the mAIEC and control bacteria was expressed as the mean percentage of the number of bacteria recovered 24 hours post-infection divided by the number of bacteria 1 hour post-infection, with the two J774A.1 cell counts being used to normalize the bacterial counts. Control bacteria were the LF82 human AIEC (kindly provided by the late Dr. Arlette DarfeuilleMichaud) and K12 (a noninvasive E. coli, ATCC 25404). 


\section{Diet High in Soybean Oil Increases Susceptibility to Colitis in Mice}

\section{Culture of mAIEC for metabolomic analysis}

The mAIEC was grown aerobically in LB broth with $10 \%$ soybean soil for 20 hours at $37^{\circ} \mathrm{C}$ with shaking at $350 \mathrm{rpm}$. The bacteria were collected by centrifugation at $14,000 \mathrm{x}$ g for 30 seconds and then removing the supernatant; this procedure was repeated two more times to remove as much of the soybean oil as possible. The bacterial pellets were flash frozen in liquid nitrogen and stored at $-80^{\circ} \mathrm{C}$ until they were analyzed. Controls were the mAIEC grown in LB broth without soybean oil as well as uninoculated LB with and without soybean oil that was subjected to incubation for 20 hours at $37^{\circ} \mathrm{C}$ with shaking at $350 \mathrm{rpm}$.

\section{Sole carbon source experiments}

mAIEC was grown aerobically in LB media for 20 hours at $37{ }^{\circ} \mathrm{C}$ at $300 \mathrm{rpm}$ and then diluted (1:50) in minimum essential medium (standard M9 medium but without glucose and supplemented with vitamins (ATCC, catalog no. MD-VS) amd trace minerals (ATCC, catalog no. MD-TMS). This medium was supplemented with either $2 \mathrm{mM}$ linoleic acid dissolved in ethanol (Cayman Chemicals, catalog no. 9015050) or an equal volume of ethanol. OD600 measurements were taken on a Synergy HTX Microplate reader at 0, 30, 90, 150, 180 and 240 minutes after inoculation.

\section{Metabolomics}

Cell pellet: non-esterified oxylipins, endocannabinoids and polyunsaturated fatty acids extraction

Cell pellet (of IECs and bacteria) was weighed prior to extraction. Oxylipins, endocannabinoids and polyunsaturated fatty acids (PUFAs) were isolated by liquid extraction protocol using acetonitrile/isopropanol/water mixture [3:3:2 v/v] from approximately $80 \mathrm{mg}$ of cell pellet and quantified by UPLC-MS/MS using internal standard methods. Briefly, $\sim 80 \mathrm{mg}$ of 


\section{Diet High in Soybean Oil Increases Susceptibility to Colitis in Mice}

cell pellet was mixed with $20 \mu \mathrm{L}$ BHT/EDTA (1:1 MeOH:water), $20 \mu \mathrm{L}$ of $1250 \mathrm{nM}$ deuterated oxylipins and endocannabinoids surrogates in methanol and $20 \mu \mathrm{L}$ of 1-cyclohexyl ureido, 3dodecanoic acid (CUDA) and 1-phenyl ureido 3-hexanoic acid (PUHA) at $5 \mu \mathrm{M}$ in 1:1 methanol:acetonitrile. Samples were then homogenized using Geno/Grinder 2010 after addition of $0.5 \mathrm{~mL}$ of acetonitrile/isopropanol/water $(3: 3: 2)$, together with three 3 -mm stainless steel beads. Homogenate was centrifuged at 15000 rcf for 10 minutes and filtered through a $0.1 \mu \mathrm{m}$ PVDF spin filter and collected for mass spectrometry analysis described below.

Bacterial culture media: non-esterified oxylipins, endocannabinoids and polyunsaturated fatty acids extraction

Non-esterified oxylipins, endocannabinoids and polyunsaturated fatty acids were isolated using solid phase extraction with $60 \mathrm{mg}$ Hydrophilic-Lipophilic-Balanced columns (Oasis, Waters Corporation, Milford, MA). Briefly, columns were washed with one column volume of ethyl acetate followed by two column volumes of methanol and further conditioned with two column volume of $5 \%$ methanol, $0.1 \%$ acetic acid in water. Next, columns were spiked with $5 \mu \mathrm{L}$ BHT/EDTA (1:1 MeOH:water) and $5 \mu \mathrm{L}$ of $250 \mathrm{nM}$ deuterated oxylipins and endocannabinoids surrogates in methanol. Samples $(200 \mu \mathrm{L})$ were mixed with $800 \mu \mathrm{L}$ of $5 \%$ methanol, $0.1 \%$ acetic acid in water, transferred onto the column and extracted under the gravity. Columns were washed with 1 column volume of $30 \%$ methanol, $0.1 \%$ acetic acid in water. Analytical targets were eluted with $0.5 \mathrm{~mL}$ methanol followed by $1.5 \mathrm{~mL}$ ethyl acetate. Eluents were dried under the vacuum, reconstituted in $50 \mu \mathrm{L}$ of 1-cyclohexyl ureido, 3-dodecanoic acid (CUDA) and 1-phenyl ureido 3hexanoic acid (PUHA) at $5 \mu \mathrm{M}$ in 1:1 methanol:acetonitrile, filtered through $0.1 \mu \mathrm{m}$ PVDF spin filter and collected for mass spectrometry analysis described below. 


\section{Diet High in Soybean Oil Increases Susceptibility to Colitis in Mice}

Mass spectrometry analysis

Residues in extracts were separated on a $2.1 \mathrm{~mm}$ x $150 \mathrm{~mm}, 1.7 \mu \mathrm{m}$ BEH C18 column (Waters, Milford, MA) and detected by electrospray ionization with multi reaction monitoring on a API 6500 QTRAP (Sciex; Redwood City, CA) and quantified against 7-9 point calibration curves of authentic standards using modifications of previously reported methods (Agrawal et al., 2017).

\section{Statistical analysis}

Data are presented as mean +/- standard error of the mean (SEM) using GraphPad Prism 6. One-way ANOVA or repeated measures (RM) ANOVA followed by post-hoc tests (Tukey's or Sidak as specified in the figure legends) for multiple comparisons or Student's T-test were used as appropriate and are indicated in the figure legends. Statistical significance was accepted at an alpha level less than or equal to 0.05 . Linear regression analysis was performed between body weight, adipose tissue weight, liver as percent body weight, colon length and relative abundance of mAIEC in intestinal epithelial cells. The following cut-offs were used to determine significance: Pearson's coefficient $r>0.5$ with $\mathrm{P} \leq 0.05$. For the metabolomics data, outliers were first removed using the robust Huber $\mathrm{M}$ test and missing data were imputed using multivariate normal imputation. Further, variables were clustered separately for each cell type using JMP Principal Component Analysis (PCA) algorithm and converted into cluster components for data reduction. Cluster components were used for PCA analysis of experimental samples to provide an overview of metabolic changes. 


\section{RESULTS}

\section{Dietary soybean oil increases susceptibility to DSS-induced colitis in WT mice}

To determine the effects of soybean oil (SO) on susceptibility to colitis, male C57BL6/N mice (WT) were fed either a diet enriched in soybean oil with added fiber $(\mathrm{SO}+\mathrm{f})(35 \mathrm{kcal} \%$ fat, $18.6 \mathrm{kcal} \% \mathrm{LA}$ ) or a low-fat vivarium (Viv) chow diet (Supplementary Table 1). Consistent with our previous studies using an SO-enriched diet lacking added fiber (Deol et al., 2015, 2017), after 15 weeks, mice on the $\mathrm{SO}+\mathrm{f}$ diet weighed significantly more than those on Viv chow (Supplementary Figure 1A). They also had shortened colon (7.9 vs $9.5 \mathrm{~cm}$ ) and crypt lengths (103 vs $116 \mu \mathrm{m}$ ) but no morphological differences were apparent in tissue sections from the distal colon (Figure 1C, Supplementary Figure 1B). When challenged after 15 weeks on the diet with 2.5\% DSS in the drinking water for 6 days, we observed a higher percent body weight loss in the SO+f group compared to the Viv chow control (13\% vs 1.8\%, respectively) (Figure 1A). Accordingly, the average weight at harvest, as a percent of weight before the start of DSS treatment, was significantly lower in the $\mathrm{SO}+\mathrm{f}$ diet mice ( $88 \%$ vs $98 \%$ in Viv chow group) (Figure $1 \mathrm{~A})$.

Since immune dysfunction is an important manifestation of IBD, we characterized immune cell populations in isolated intestinal epithelial lymphocytes (IELs) and lamina propria lymphocytes (LPLs) from both naive and DSS-treated Viv chow and SO+f diet mice. A significant increase in the eosinophil population in the intestinal LPLs was observed in SO+f mice after DSS treatment (Figure 1B) but not in untreated mice (Supplementary Figure 1C, D). No significant differences were observed for monocytes or neutrophils in the LPLs, nor in any of the immune cell populations in the IELs (Figure 1B). Histological analysis of the distal colon from DSS-treated Viv chow and $\mathrm{SO}+\mathrm{f}$ diet mice shows that the latter have extensive loss of crypt structure, more immune cell infiltrate and thickened muscularis (Figure 1C and Supplementary Figure 1E). Taken 


\section{Diet High in Soybean Oil Increases Susceptibility to Colitis in Mice}

together, these results suggest that there is greater immune dysfunction following DSS treatment in the mice on the $\mathrm{SO}+\mathrm{f}$ diet.

DSS treatment caused colon lengths to shorten further in the $\mathrm{SO}+\mathrm{f}$ group $(7.9$ to $5.6 \mathrm{~cm}$, $29 \%$ decrease); colon length of the Viv chow mice also decreased compared to the untreated controls, but significantly less so (9.5 to $7.7 \mathrm{~cm}, 19 \%$ decrease) (Figure 1C). Crypt length measurements revealed a similar pattern as colon length, with DSS treatment shortening the crypts in both groups but with only the $\mathrm{SO}+\mathrm{f}$ mice showing a significant difference (103.4 to $92.5 \mu \mathrm{m}$, $10.5 \%$ decrease for $\mathrm{SO}+\mathrm{f}$ ) (Figure $1 \mathrm{C}$ ). As with greater immune dysfunction, decreased colon and crypt lengths are correlated with increased colonic inflammation (Adachi et al., 2006; Lee et al., 2007).

\section{Dietary soybean oil accelerates onset of colitis in IL10 deficient mice}

To determine whether soybean oil can affect susceptibility to colitis in a genetic model of IBD susceptibility, IL-10 deficient mice (IL-10-/-) (B6 strain which develops a mild form of colitis) were fed either the Viv chow or SO+f diet for 10 weeks. IL-10-/- mice on the $\mathrm{SO}+\mathrm{f}$ diet had accelerated development of disease indices of colitis -- i.e, body weight loss starting at 6 weeks and appearance of blood in the stool after 4 weeks on the diet. In contrast, these symptoms did not become apparent in the Viv chow group until after 9 weeks (Figure 1D and E). Even though both groups of mice had similar weights at the beginning of the dietary treatments, the $\mathrm{SO}+\mathrm{f}$ diet mice had significantly lower body weights than the Viv chow group at the time of harvest (Figure 1D). This is notable given that the $\mathrm{SO}+\mathrm{f}$ diet is a high-fat, high-caloric diet. Colon lengths of the two diet groups were similar and there were no obvious differences in gross colonic histology but the $\mathrm{SO}+\mathrm{f}$ diet significantly shortened crypt length compared to the Viv chow group (142.8 vs 158.3 


\section{Diet High in Soybean Oil Increases Susceptibility to Colitis in Mice}

$\mu \mathrm{m}, 9.8 \%$ decrease) (Figure 1F and Supplementary Figure 2B). It has been reported previously that IL-10 ${ }^{-/-}$mice have elongated crypts compared to WT mice (Berg et al., 1996; Lee et al., 2007). We see a similar pattern of elongated crypts in IL-10 $0^{-/-}$mice on both diets as in WT mice (Figure $1 \mathrm{~F}$ vs $1 \mathrm{C}$ ) and no effect on overall small intestines length by the $\mathrm{SO}+\mathrm{f}$ diet (or spleen weight, although the $\mathrm{SO}+\mathrm{f}$ diet does decrease the liver as a percent body weight) (Supplementary Figure 2A).

\section{Dietary soybean oil overcomes resistance to DSS-induced colitis in HNF4a exon swap mice}

To determine whether soybean oil can impact susceptibility to colitis in a genetic model of IBD resistance, we examined the effect of the $\mathrm{SO}+\mathrm{f}$ diet on DSS-induced colitis in HNF4 $\alpha$ exon swap mice which express only the P1 isoform of HNF4 $\alpha(\alpha 1 \mathrm{HMZ})$ (Figure 2A). We have previously shown that $\alpha 1 \mathrm{HMZ}$ male mice exhibit resistance to DSS-induced colitis on Viv chow while mice expressing only the P2 isoforms of HNF4 $\alpha$ are highly sensitive (Chellappa et al., 2016). The $\alpha 1 \mathrm{HMZ}$ male mice fed the $\mathrm{SO}+\mathrm{f}$ diet did not show significant weight gain compared to the Viv chow group until 19 weeks on the diet vs 10 weeks for the WT mice (Supplementary Figure 3A vs Supplementary Figure 1A). When treated with $2.5 \%$ DSS for 6 days, similar to the WT mice, the $\alpha 1 \mathrm{HMZ} \mathrm{SO}+\mathrm{f}$ diet mice lost significantly more weight $(10.2 \%)$ than the Viv chow controls (1.7\%) (Figure 2B). In contrast, the percent weight loss was somewhat less in $\alpha 1 \mathrm{HMZ}$ mice than in the WT mice (13.8\% for SO+f and 1.8\% for Viv chow) (Supplementary Figure 3D).

As in the WT mice, DSS treatment of $\alpha 1 \mathrm{HMZ}$ mice caused greater loss of crypt structure and more immune cell infiltration in the $\mathrm{SO}+\mathrm{f}$ diet group compared to the Viv chow control (Figure $2 \mathrm{C}$ and Supplementary Figure $3 \mathrm{E})$. At 15 weeks on the diet, the colon length in $\alpha 1 \mathrm{HMZ} \mathrm{SO}+\mathrm{f}$ fed mice was trending lower than the Viv chow group but was not significant $(8.8 \mathrm{vs} 10 \mathrm{~cm}, P=0.06)$; 


\section{Diet High in Soybean Oil Increases Susceptibility to Colitis in Mice}

in contrast, there was no difference in crypt lengths between the two diets in $\alpha 1 \mathrm{HMZ}$ mice (Figure 2C). Similar to WT mice, colon length in the $\mathrm{SO}+\mathrm{f} \alpha 1 \mathrm{HMZ}$ mice decreased significantly with DSS treatment $(8.8$ to $5.1 \mathrm{~cm})$ and was significantly shorter than the DSS-treated Viv chow group (7.4 $\mathrm{cm})$. DSS treatment also significantly decreased crypt length in SO+f $\alpha 1 \mathrm{HMZ}$ mice compared to the untreated SO+f group (160 vs $140 \mu \mathrm{m}, 12.5 \%$ decrease). However, in $\alpha 1 \mathrm{HMZ}$ mice there was no significant difference in crypt length between Viv chow and $\mathrm{SO}+\mathrm{f}$ diet either with or without DSS treatment (Figure 2C), as there was in WT mice (Figure 1C). Taken together, these results show that while the $\mathrm{SO}+\mathrm{f}$ diet had less of an impact in $\alpha 1 \mathrm{HMZ}$ compared to WT mice in the absence of DSS treatment, dietary soybean oil nonetheless led to increased IBD susceptibility upon DSS treatment even in these "DSS-resistant" mice, confirming again the ability of dietary soybean oil to increase susceptibility to colitis.

Immune cell analysis revealed an increase in immune cells after DSS treatment in the $\alpha 1 \mathrm{HMZ}$ mice on the $\mathrm{SO}+\mathrm{f}$ diet although the profile was different than that observed in WT mice (Figure 2D). While the $\mathrm{SO}+\mathrm{f}$ diet did not alter eosinophil levels in the LPLs in the $\alpha 1 \mathrm{HMZ}$ mice as it did in WT mice (Figure 1B), there was a significant increase in neutrophils in the LPL population and monocytes in the IEL population with the SO+f diet (Figure 2D). Like the WT mice, there were no significant differences observed in $\alpha 1 \mathrm{HMZ}$ mice in the PBMCs on the two different diets (Supplementary Figure 3C).

\section{Dietary soybean oil increases intestinal barrier dysfunction: role for colonic HNF4a isoforms}

Having established that the $\mathrm{SO}+\mathrm{f}$ diet increases susceptibility to colitis in three different mouse models -- DSS WT, IL-10-/ (IBD-sensitive), $\alpha 1 \mathrm{HMZ}$ (IBD-resistant) -- we next investigated the underlying mechanisms by examining intestinal epithelial barrier function using 


\section{Diet High in Soybean Oil Increases Susceptibility to Colitis in Mice}

the FITC-Dextran assay. We found that after 12 weeks, the $\mathrm{SO}+\mathrm{f}$ diet significantly increased epithelial permeability (measured by increased FITC-Dextran in the serum) in both WT and a1HMZ mice (Figure 2E). To determine whether this barrier defect could be reversed by changing the diet, we fed a third group of mice, for both genotypes, the SO+f diet for 8 weeks, followed by 4 weeks of Viv chow. We found that while the barrier permeability in WT mice remained elevated even after the diet reversal, in $\alpha 1 \mathrm{HMZ}$ mice replacing the $\mathrm{SO}+\mathrm{f}$ diet with Viv chow significantly improved barrier function (Figure 2E).

Immunoblot (IB) analysis of distal colon whole cell extracts showed an increase in the P2$\mathrm{HNF} 4 \alpha$ isoform in the colons of WT mice fed the SO+f diet. Changing the diet to Viv chow did not significantly decrease the P2-HNF4a levels, suggesting that the SO+f diet causes an irreversible imbalance in the intestinal expression of the HNF4 $\alpha$ isoforms (Figure 2F). This could explain the lack of rescue of barrier function by Viv chow in WT mice (Figure 2E): we have reported previously that mice expressing only the P2-HNF4 $\alpha$ isoform have reduced intestinal epithelial barrier function (Chellappa et al., 2016). In contrast, the level of P1-HNF4 $\alpha$ protein on the $\mathrm{SO}+\mathrm{f}$ diet in WT (and $\alpha 1 \mathrm{HMZ}$ ) mice was not significantly altered (Figure $2 \mathrm{~F}$ and Supplementary Figure 4). Taken together, these results suggest that a soybean oil diet may increase susceptibility to colitis in part by increasing the expression of the P2-HNF4 $\alpha$ isoform in the intestines, thereby compromising epithelial barrier function.

\section{Soybean oil diet causes an increase in intestinal mAIEC}

Another potential mechanism by which a soybean oil diet may increase IBD susceptibility is via alteration of the gut microbiome. Examination of the intestinal microbiota revealed that a diet enriched in soybean oil causes dysbiosis of the bacteria associated with the intestinal epithelial 


\section{Diet High in Soybean Oil Increases Susceptibility to Colitis in Mice}

cells, with a notable increase in the relative abundance of a specific Escherichia coli phylotype (Figure 3A). Since a portion of the rRNA ITS region of this E. coli phylotype had $100 \%$ sequence identity with an AIEC we recently characterized in another genetic mouse model of IBD susceptibility (Shawki et al., 2020), we conducted a phenotypic characterization of the isolate. In Caco- brush border epithelial (Caco-2BBE) cells, the E. coli isolate had adherence and invasion values slightly less than those from the well characterized AIEC LF82, which is associated with IBD in humans (Darfeuille-Michaud et al., 2004); it also showed greater replication in murine macrophages (J774A.1) than LF82 AIEC (Figure 3B). Since LF82 is a human isolate, we would not expect it to invade and replicate in mouse macrophages as the putative mouse AIEC. On the other hand, since $\mathrm{CaCo} 2$ is a human derived cell line, we would expect LF82 to adhere to and invade these cells more effectively than our putative mouse AIEC. These results confirmed that the $E$. coli phylotype and isolate, which increased in abundance in the intestines of mice fed a high soybean oil diet, is indeed an AIEC; we will henceforth refer to this bacterium as SO mAIEC, the full name being UCR-SoS5.

Correlation analysis shows a positive correlation between the intestinal abundance of the SO mAIEC with body weight and adipose tissue weight (mesenteric, subcutaneous, perirenal and gonadal) (Figure 3C). On the other hand, colon length shows a modest negative correlation with SO mAIEC abundance (Figure 3D), raising the possibility that this bacterium could play a role in the reduction of colon length in mice fed the $\mathrm{SO}+\mathrm{f}$ diet (Figure 1C). Since liver as a percent body weight also decreased with increasing SO mAIEC levels (Figure 3D), these results suggest that the intestinal dysbiosis induced by a soybean oil diet could potentially have effects outside of the gut. 


\section{Diet High in Soybean Oil Increases Susceptibility to Colitis in Mice}

\section{SO mAIEC can accumulate, utilize and metabolize linoleic acid}

To further investigate the link between a soybean oil diet and the SO mAIEC, we conducted a metabolomic analysis of SO mAIEC grown in vitro in media (Luria broth, LB) with or without soybean oil, and examined the metabolomes of both the bacteria and the media (Figure 4A, Supplementary Figure 5 B, C). Since soybean oil is high in polyunsaturated fats (PUFAs: 53\% LA and 7\% alpha-linolenic acid, ALA, C18:3 $\omega 3$ ), we used a platform that allows for identification of bioactive metabolites of PUFAs, including LA metabolites such as oxylipins and endocannabinoids. Principal components analysis (PCA) of the results shows a notable difference in the profiles obtained for SO mAIEC grown in the absence or presence of soybean oil (Figure 4A). This difference was driven mainly by the levels of the omega-6 LA and the omega-3 ALA and their epoxy-derivatives (Cluster 10), and the omega-3 eicosapentaenoic acid (EPA), which is derived from ALA, and its metabolites (Cluster 12) (Supplementary Figure 5A and Supplementary Table 2). The levels of LA and ALA were increased significantly in SO mAIEC grown in the presence of soybean oil compared to control media (Figure 4B, Supplementary Figure 5C). Similarly, levels of three oxylipin metabolites of LA (9-KODE, 9, 10-EpOME and 12,13-EpOME) were increased in SO mAIEC grown in the presence of soybean oil compared to control media (Figure 4 C, Supplementary Figure 5C). In contrast to LA, the omega-3 PUFA EPA was at lower levels in bacteria grown in the presence of soybean oil (Figure 4B). Taken together, these results indicate that the SO mAIEC isolate can accumulate and metabolize LA from soybean oil.

Arachidonic acid (AA), a pro-inflammatory fatty acid derived from LA, did not show a difference in levels in SO mAIEC grown with or without soybean oil (Supplementary Figure 5B). However, the endocannabinoid anandamide (AEA), which is derived from AA, and closely related $N$-acylethanolamines -- N-palmitoylethanolamine (PEA), N-oleoylethanolamine (OEA), N- 


\section{Diet High in Soybean Oil Increases Susceptibility to Colitis in Mice}

stearoylethanolamine (SEA), N-dihomo- $\gamma$-linolenoylethanolamide (DGLEA), eicosapentaenoyl ethanolamide (EPEA), palmitoleoyl ethanolamide (POEA) -- as well as N-oleyl glycine (NOGLY) are all decreased in SO mAIEC when the growth media is supplemented with soybean oil (Figure 4D). More importantly, all of the levels of endocannabinoids in the growth media were significantly lower than in the bacteria themselves, suggesting that the SO mAIEC may be able to produce these neurotransmitters. The results also suggest that their production is blocked by the presence of soybean oil.

To determine whether the SO mAIEC can utilize LA as an energy source, we grew SO mAIEC in a minimal medium (M9) supplemented with either ethanol or LA (dissolved in ethanol) as the sole source of carbon. The SO mAIEC grew significantly better in the presence of LA (Figure 4E), suggesting that the SO mAIEC may have a growth advantage in the LA-rich environment of a soybean oil diet.

\section{Intestinal epithelial barrier function is affected by dietary soybean oil in germ-free mice}

Our results thus far suggest that SO may induce IBD susceptibility by providing an environment conducive for the outgrowth of the pathobiont SO mAIEC, which in turn increases the levels of LA oxylipins and decreases the levels of endocannabinoids in the gut. To determine whether the host can also contribute to alterations in the gut metabolome, we employed a germfree (GF) mouse model. GF animals are known to lack the protective mucosal layer due to the absence of bacteria (Schroeder, 2019) and hence are extremely sensitive to epithelial injury during DSS treatment (Hernández-Chirlaque et al., 2016). Therefore, we examined intestinal epithelial barrier function in both GF and conventionally raised (Conv) mice using the FITC Dextran assay as an indicator of IBD susceptibility (Martini et al., 2017). 


\section{Diet High in Soybean Oil Increases Susceptibility to Colitis in Mice}

Consistent with Figure 2E, the $\mathrm{SO}+\mathrm{f}$ diet significantly increased barrier permeability in Conv mice fed SO+f for 12 weeks versus the Viv chow group (Figure 5A). GF mice on SO+f also had increased barrier permeability compared to the Viv chow group but this difference was not significant. In contrast, FITC levels in GF SO+f mice were significantly $(P<0.001)$ greater than in the Conv SO+f mice (Figure 5A). Interestingly, even on Viv chow, GF mice displayed increased barrier permeability compared to Conv mice, although the difference did not quite reach significance $(P=0.06)$ (Figure 5A). This is not unexpected since lack of a functional gut microbiota is known to decrease mucus layer thickness and increase epithelial permeability (Sommer and Backhed, 2013). Taken together, these results suggest that some component, or hostderived metabolite, of the $\mathrm{SO}+\mathrm{f}$ diet can exacerbate barrier dysfunction in GF mice.

To determine which metabolites might be involved in compromising the barrier function we applied the same metabolomic analysis as in Figure 4 to the IECs isolated from Conv and GF mice fed either the Viv chow or the $\mathrm{SO}+\mathrm{f}$ diet. We chose a shorter time on the diet (eight weeks) in order to identify compounds that might cause barrier dysfunction without the confounding factor of excessive adiposity seen at later time points. At eight weeks on the diet, there was no difference in body weight between the GF Viv chow and $\mathrm{SO}+\mathrm{f}$ mice and serum FITC levels are just beginning to increase in Conv $\mathrm{SO}+\mathrm{f}$ mice (SO+f: 0.52 and $1.14 \mu \mathrm{g} / \mathrm{ml}, 8$ and 12 weeks, respectively; versus Viv chow: $0.31 \mu \mathrm{g} / \mathrm{ml}$ at both time points) (Supplementary Figure 5 D, E and Figure 5A). PCA analysis shows that the two dietary groups $(\mathrm{SO}+\mathrm{f}$ and $\mathrm{Viv}$ chow) are separated from each other regardless of the microbiome status (conventional or germ-free) of the mice. Variables with the largest contribution to this separation were EPA and docosahexaenoic acid (DHA) and their lipoxygenase and soluble epoxide hydrolase derivatives (Cluster 1) (Supplementary Figure 5F and Supplementary Table 2). 


\section{Diet High in Soybean Oil Increases Susceptibility to Colitis in Mice}

In order to better decipher the contributions of diet and the microbiota to the gut metabolome, we conducted a comparative analysis of the metabolites that were significantly dysregulated in IECs harvested from the various conditions: Viv chow vs SO+f diet and Conv vs GF mice (Figure 5C). Analysis of metabolites dysregulated by diet identified a total of 27 oxylipins that were significantly dysregulated in the IECs isolated from Conv mice fed Viv chow vs the $\mathrm{SO}+\mathrm{f}$ diet ( 9 up and 18 down by $\mathrm{SO}+\mathrm{f}$ ) and 30 that differed between the GF mice fed Viv chow vs the $\mathrm{SO}+\mathrm{f}$ diet ( 8 up and 22 down by $\mathrm{SO}+\mathrm{f}$ ) (Figure 5C and Supplementary Figure 6). Of these, 21 compounds are commonly dysregulated (and in the same direction), suggesting that diet and/or host cells rather than bacteria play a role in their accumulation/metabolism (Supplementary Figure $6)$.

Analysis of metabolites whose levels are significantly altered by the microbiome, regardless of diet (Conv to GF comparison for both Viv chow and SO+f diets), identified 33 metabolites that differ in the Viv comparison and 18 in the $\mathrm{SO}+\mathrm{f}$ comparison (Figure 5C and Supplementary Figure 7). Of these, 11 are common to both GF and Conv mice, suggesting that the presence or absence of gut microbiota is the determining factor for these metabolites rather than diet.

Levels of LA, ALA and EPA were significantly altered in the GF vs Conv comparison as well as the Viv chow vs SO+f comparison (Figure 5D), indicating that they are dysregulated by both the microbiome and diet. In contrast, host cells rather than bacteria appear to play a primary role in the accumulation/metabolism of the LA-derived oxylipin 12,13-DiHOME and the ALAderived oxylipin 12,13-DiHODE, since both Conv and GF mice fed the SO+f diet show decreased levels of these metabolites in the IECs (Figure 6A). In Conv mice, two oxidized LA metabolites, 13-HODE and 13-KODE, and the ALA-derived 13-HOTE are increased in the SO+f fed group 


\section{Diet High in Soybean Oil Increases Susceptibility to Colitis in Mice}

(Figure 6A). 13-HODE and 13-KODE are also increased in GF mice fed Viv chow vs the Conv Viv group but none of these are changed in the GF Viv vs $\mathrm{SO}+\mathrm{f}$ comparison suggesting a role for both microbes and diet/host in their production.

AA levels were significantly higher in GF mice fed the SO+f diet compared to the GF Viv chow counterparts, as well as Conv mice on the SO+f diet (Figure 6B). This indicates that AA levels can be affected by both diet/host and microbiome status. AA-derived endocannabinoids were similarly dysregulated by both gut microbiota and diet (Figure 6C). Of these, AEA, OEA and NA-Gly are increased due to lack of microbes, regardless of diet; while high SO diet decreased NA-Gly in GF mice (Figure 6C). EPEA (derived from EPA) and POEA (derived from palmitoleic acid) are also decreased by high dietary soybean oil in GF mice (Figure 6D). In contrast, oleic acid-derived NO-Gly is increased by soybean oil in the absence of microbes, indicating significant dysregulation by both diet and lack of gut microbes (Figure 6D).

\section{DISCUSSION}

While the role of saturated fat in the pathophysiology of IBD is well established (KnightSepulveda et al., 2015)PUFA-rich soybean oil. Therefore, in this study we examined the effect of a diet enriched in soybean oil comparable to the American diet in terms of amount of total fat (35 $\mathrm{kcal} \%$ ) on the development of colitis in mice. Our findings are important because not only is soybean oil the most highly consumed edible oil in the U.S., its increase in consumption parallels the rise in IBD incidence in the U.S. (Molodecky et al., 2012; USDA Economic Research Service, 2020) and its global consumption is increasing rapidly (USDA Economic Research Service, 2020).

Here, we show that a high fat diet comprised of soybean oil is a predisposing factor for IBD in three different mouse models of colitis -- DSS-induced, IL-10 $0^{-/}$and HNF4 $\alpha$ transgenic 


\section{Diet High in Soybean Oil Increases Susceptibility to Colitis in Mice}

mice. We demonstrate that dietary soybean oil decreases intestinal epithelial barrier function and that modulation of the gut microbiome and metabolome, as well as IBD susceptibility gene HNF4 $\alpha$, may be involved (Figure 7). Specifically, we found that in male mice the soybean oil diet: i) increases the abundance of MAIEC, a pathobiont that has been shown to cause colitis in mice (Shawki et al., 2020); ii) increases the level of P2-HNF4 $\alpha$ in the colon; iii) increases proinflammatory PUFA metabolites, oxylipins; and iv) decreases levels of anti-inflammatory bioactive lipids, including endocannabinoids and the omega-3 EPA. Our results indicate that fiber is not a major factor in these effects: unlike most high fat diet studies, the fiber in our soybean oil $\operatorname{diet}(\mathrm{SO}+\mathrm{f})$ was comparable to that in the low-fat, high-fiber control diet (Viv chow)

\section{Role of mAIEC and linoleic acid in soybean oil-induced IBD susceptibility}

Reduction in the diversity of gut bacterial species and an increase in host-associated microbes has been described not only in mouse models of IBD but also in patients suffering from the disease (Gkouskou et al., 2014; Kaur et al., 2011). Beneficial bacteria have been shown to be decreased in IBD while microbial pathogens such as AIEC are increased (Alam et al., 2020; Darfeuille-Michaud et al., 2004). The first AIEC strain (LF-82) associated with human IBD was isolated from a patient with Crohn's Disease ((Alam et al., 2020; Darfeuille-Michaud et al., 2004). We recently identified a novel mouse AIEC (mAIEC) strain with adherence, invasive and replication properties comparable to LF-82 (Shawki et al., 2020). In this study, we report that a diet high in soybean oil can increase the population of a related mAIEC in the mouse intestinal tract; we refer to it as SO mAIEC. The outgrowth of SO mAIEC could be due to the fact that it can use the major component of soybean oil, linoleic acid (LA, C18:2 omega 6), as an energy source (Figure 4). 


\section{Diet High in Soybean Oil Increases Susceptibility to Colitis in Mice}

Not unexpectedly, levels of LA as well as ALA (C18:3 omega-3, also found in soybean oil although at lower levels than LA) increased in the intestinal epithelial cells (IECs) of both germfree and conventional mice fed the soybean oil diet compared to the low fat control diet (Figure 5). Less anticipated was the increased levels of these PUFAs in germ-free mice compared to conventional mice regardless of diet (Figure 5). The in vitro results from the SO mAIEC, which also had elevated LA and ALA levels in the presence of soybean oil, offer an explanation: gut microbiota can evidently accumulate and metabolize LA and ALA so when they are absent, as in the germ-free mice, the levels of these PUFAs are elevated.

\section{Role of HNF4 $\alpha$ isoforms in soybean oil-induced IBD susceptibility}

We have previously shown that increased intestinal expression of P2-HNF4 $\alpha$ (relative to P1-HNF4 $\alpha$ ) leads to decreased barrier function and increased DSS-induced colitis (Chellappa et al., 2016). Here, we report that the soybean oil diet causes increased epithelial permeability along with an increase in P2-HNF4 $\alpha$ protein (Figure 2), suggesting that an imbalance of the HNF4 $\alpha$ isoforms in the gut may play a role in SO-induced IBD susceptibility (Figure 7). The cause of the increase in expression of $\mathrm{P} 2-\mathrm{HNF} 4 \alpha$ remains to be determined. One possibility is that the dysbiosis caused by the soybean oil diet is responsible as HNF4 $\alpha$ expression has been shown to be modulated by the microbiome (Davison et al., 2017), although the different isoforms were not examined in that study.

Another possibility is that LA alters the balance of the HNF4 $\alpha$ isoforms. We previously identified LA as the endogenous ligand for HNF4 $\alpha$ and showed that it can decrease its transcriptional activity and protein stability (Yuan et al., 2009). However, since both P1- and P2- 


\section{Diet High in Soybean Oil Increases Susceptibility to Colitis in Mice}

HNF $4 \alpha$ contain identical ligand binding domains, any potential impact of LA on the HNF4 $\alpha$ isoform balance would likely be a complex one.

\section{Role of increased oxylipin levels in soybean oil induced IBD susceptibility}

LA and ALA oxylipins are bioactive, pro-inflammatory molecules that have been recently linked to IBD (Diab et al., 2019; Marton et al., 2019). Increased levels of these compounds in the intestines of soybean oil-fed mice is reminiscent of our previous findings showing that LA and ALA oxylipin levels in the liver correlate with obesity, another condition linked to chronic inflammation (Deol et al., 2017; Ellulu et al., 2017). Interestingly, the SO mAIEC, as well as host cells, are able to produce LA and ALA oxylipins, presumably from the high LA and ALA levels in soybean oil (Figures 4 and 6). The positive association between the oxylipins and reduced barrier function and increased colitis susceptibility caused by the soybean oil diet is intriguing; it remains to be determined whether they also play a casual role.

\section{Role of decreased endocannabinoids and EPA in soybean oil-induced IBD susceptibility}

Apart from the LA/ALA oxylipins, the other most significantly dysregulated group of metabolites in both the in vitro bacterial and in vivo mouse metabolomic analyses were endocannabinoids: the presence of soybean oil caused a significant decrease in at least two of these compounds in both systems, eicosapentaenoyl ethanolamide (EPEA), palmitoleoyl ethanolamide (POEA) (Figures 4 and Figure 6). Particularly intriguing was the fact that SO mAIEC grown in the presence of soybean oil had lower levels of the endocannabinoids than the bacteria grown in the absence of soybean oil, suggesting that some component of soybean oil, or some pathway activated by soybean oil in the bacteria, blocked their production. One such endocannabinoid is 


\section{Diet High in Soybean Oil Increases Susceptibility to Colitis in Mice}

palmitoylethanolamide (PEA) which has been shown to increase the resistance to bacterial infections (Redlich et al., 2014). These results are consistent with the fact that a decrease in endocannabinoid levels is associated with increased colitis (Diab et al., 2019) and that endocannabinoids are increasingly being explored for potential therapeutic activity against IBD (Cani et al., 2016).

In contrast to LA and ALA, EPA -- one of the best studied omega-3 PUFAs in terms of beneficial health effects -- was significantly decreased in both the in vitro and in vivo metabolomes in the presence of soybean oil. This is despite the fact that its parent fatty acid ALA is enriched roughly 30 -fold in the soybean oil diet ( $3 \mathrm{kcal} \%$ in $\mathrm{SO}+\mathrm{f}$ vs $0.1 \mathrm{kcal} \%$ in Viv chow) and suggests that some aspect of the metabolic pathway for the conversion of ALA to EPA is compromised by dietary soybean oil in the host cells. Additionally, we observed higher levels of EPA in the germfree mice compared to the conventional ones, suggesting that the gut microbiota also play a role on EPA levels. This is consistent with the fact that EPA is decreased in MAIEC in vitro and suggests that pathobionts may decrease levels of this omega-3 fatty acid in vivo.

Many EPA metabolites, which are considered to be anti-inflammatory e.g., DiHETEs, HEPEs, PGF3a (Gabbs et al., 2015; Ramstedt et al., 1984) were also decreased by the soybean oil diet (Supplementary Figure 6). The decrease was often observed in both the germ-free and conventional mice, suggesting a host rather than a bacterial effect. Additionally, the fact that some of these potentially beneficial oxylipin metabolites of EPA were increased in mAIEC grown in media supplemented with soybean oil (e.g., PGF3a and 14,15-DiHETE, Supplementary Figure 5), suggests a complex interplay between the microbiome and the metabolome.

Overall, the decrease in omega-3 EPA and several of its metabolites, coupled with the increase in omega-6 LA and its metabolites is expected to generate a pro-inflammatory state 


\section{Diet High in Soybean Oil Increases Susceptibility to Colitis in Mice}

commonly found in IBD patients (Lee et al., 2018). Consistently, immune dysfunction was noted in WT mice fed soybean oil (Figure 1) and could be related to a pro-inflammatory state caused by an elevated omega-6/omega-3 ratio (Calder, 2005; Chapkin et al., 2007). Furthermore, a1HMZ mice, which were somewhat resistant to colitis, had a different immune profile (Figure 2).

In conclusion, this study shows that a soybean oil-enriched diet based on the current American diet can increase the susceptibility of male mice to IBD. The mechanism(s) thus far appear to involve dysregulation of the gut microbiome, potentially triggered by the high LA content of soybean oil, which provides an intestinal pathobiont a competitive growth advantage. This bacterium (mAIEC) in turn contributes to an altered gut metabolome with increased oxylipins and decreased endocannabinoids and EPA. The net result is a proinflammatory environment characteristic of IBD. One or more of these conditions may disrupt the imbalance of the HNF4 $\alpha$ isoforms, leading to impaired barrier function (Figure 7). While we know that fiber does not play a major role in these effects, future studies are needed to compare these effects of soybean oil to other high fat diets, determine whether there is a certain amount of dietary soybean oil that triggers the negative effects and verify that the effects observed in mouse are similar to those in humans. 


\section{FIGURE LEGENDS}

Figure 1. Soybean oil diet increases IBD susceptibility in male mice. WT mice fed the vivarium chow (Viv) or the soybean oil-enriched diet $(\mathrm{SO}+\mathrm{f})$ for 15 weeks were treated with $2.5 \% \mathrm{DSS}$ as indicated for six days: A) \% weight loss, weight at harvest; B) immune cell analysis (Eos, eosinophils; Mono, monocytes; Neutro, neutrophils); C) colonic histology, colon length and crypt length (at least 10 crypts were measured per mouse) Big arrow, immune infiltrate; small arrow, loss of crypt structure; line, thickening of muscularis in SO+f. Additional sections are shown in Supplementary Figure 1. IL10 $0^{-/-}$mice fed SO+f or Viv diet for 10 weeks: D) Average weekly body weights, weight at harvest; E) hemoccult assay; F) colonic histology, colon length and crypt length. of. Additional sections are shown in Supplementary Figure 2.: * vs other diet, ${ }^{\text {a }}$ vs untreated WT Viv, ${ }^{\mathrm{b}}$ vs untreated WT SO+f. T-test. $P<0.05 \mathrm{~N}=5-12$ per group.

Figure 2. Soybean oil diet increases IBD susceptibility in $\alpha 1 \mathrm{HMZ}$ mice and decreases barrier

function in WT and $\alpha \mathbf{1 H M Z}$ mice. A) Schematic of the mouse Hnf4a gene showing the two promoters (P1 and P2) (top), and the exon-swap (1D to 1A) that drives the expression of only P1HNF4 $\alpha$ in $\alpha 1 \mathrm{HMZ}$ mice (bottom). $\alpha 1 \mathrm{HMZ}(\alpha 1)$ mice on Viv chow or $\mathrm{SO}+\mathrm{f}$ diet for 15 weeks were treated with $2.5 \%$ DSS in drinking water for 6 days as indicated: B) $\%$ weight loss, weight at harvest, * vs $\alpha 1$ Viv $P<0.05$, T-test. N=3-4 per group; C) colonic histology, colon length and crypt length (at least 10 crypts were measured per mouse), ${ }^{a}$ vs untreated al Viv; ${ }^{b}$ vs untreated a1 $\mathrm{SO}+\mathrm{f} P<0.05$ vs other diet, 1-way ANOVA, Tukey's post-hoc. N=3-4 per group. D) immune cell analysis, * vs a1 Viv $P<0.05$, T-test. $\mathrm{N}=3-4$ per group. E) Epithelial barrier permeability measured by appearance of FITC dextran $(4 \mathrm{kDa})$ in serum of WT and $\alpha 1 \mathrm{HMZ}$ mice fed either Viv or SO+f diets for 12 weeks or SO+f for 8 weeks, followed by 4 weeks of Viv (Reversed) (one 


\section{Diet High in Soybean Oil Increases Susceptibility to Colitis in Mice}

outlier removed from WT reversed group). * vs Viv ** vs Viv and Reversed $P<0.05$, one-way ANOVA, Sidak's post hoc comparison. N=6-22 per group. F) Quantification of the P1-and P2HNF4 $\alpha$ immuno blot signals normalized to total protein, as determined by actin staining of the same blot. ${ }^{*} P<0.05$, one-way ANOVA, Tukey's post hoc comparison. $\mathrm{N}=3-4$ per group.

Figure 3. Soybean oil diet increases abundance of mAIEC in WT mouse intestines. A) Bacterial species plots of intestinal epithelial cells (IECs) from the small and large intestines (N=45) of mice fed Viv chow or a diet enriched in soybean oil, with no added fiber (SO). B) Phenotypic characterization of the $E$. coli isolate enriched by SO (mAIEC), compared with the human AIEC LF82 and the noninvasive E. coli K12. Assessments were made for bacterial adherence to CaCo2BBe cells, intracellular invasion of $\mathrm{CaCo}-2 \mathrm{BBe}$ cells, and replication in J774A.1 murine macrophages. * $P<0.05$, one-way ANOVA, Tukey's post hoc comparison. N=12 across 4 experiments. C) Correlation between indicated mouse metadata and $\log 10$ of mAIEC relative abundance in the small and large IECs of mice fed Viv or SO+f diets. Pearson correlation coefficient ( $\mathrm{r}$ ) and goodness of fit or $\mathrm{R}^{2}$ values for linear regression are indicated on the graphs. $\mathrm{P}$ value of the correlations $(P)$ is 0.0007 for body weight, 0.001 for mesenteric fat, 0.006 for subcutaneous fat, 0.005 for retroperitoneal fat, 0.002 for gonadal fat, $<0.001$ for liver as percent body weight and 0.05 for colon length.

Figure 4. Soybean oil diet increases oxylipins and decreases endocannabinoids in SO mAIEC cultured in vitro. A) Experimental workflow for and Principal Components Analysis (PCA) of oxylipin and endocannabinoid metabolites in mAIEC grown with or without soybean oil in media. Absolute levels of fatty acids (B), oxylipin metabolites (C) and endocannabinoids (D) measured 


\section{Diet High in Soybean Oil Increases Susceptibility to Colitis in Mice}

in $\mathrm{mAIEC}$ grown in vitro in the presence or absence of $\mathrm{SO}$ in the media. $* P<0.05, \mathrm{~T}$-test. $\mathrm{N}=6$ per group. E) Growth curves for mAIEC grown in Minimum Essential Medium (M9) with linoleic acid or vehicle (ethanol) as the carbon source. $* P<0.05$, T-test. $\mathrm{N}=4$ independent experiments.

Figure 5. Soybean oil diet decreases barrier function and alters the metabolome in the intestines of conventionally raised and germ-free mice. A) Epithelial barrier permeability measured by appearance of FITC dextran $(4 \mathrm{kDa})$ in serum of conventionally raised (Conv) and germ-free (GF) mice fed either Viv chow or SO+f diet for 12 weeks. $\mathrm{N}=3-13$ per group. ${ }^{\text {a }} P<0.05$ vs Conv Viv, ${ }^{\mathrm{b}} P<0.001 \mathrm{GF} \mathrm{SO}+\mathrm{f}$ vs Conv SO+f, $P=0.06$ Conv Viv vs GF Viv, T-test. N=3-13 per group. B) Principal Components Analysis (PCA) of oxylipin and endocannabinoid metabolites in IECs isolated from Conv and GF mice fed either Viv chow or SO+f diet for 8 weeks. $\mathrm{N}=6$ per group. C) Schematic and Venn analysis of metabolomics data in B). D) Absolute levels of fatty acids measured in IECs from Conv and GF mice fed either Viv chow or SO+f diets for 8 weeks. ${ }^{\text {a }}$ vs Conv Viv, ${ }^{\mathrm{b}}$ vs Conv SO+f, ${ }^{\mathrm{c}}$ vs GF Viv $P<0.05$, one-way ANOVA, Tukey's post hoc. $\mathrm{N}=6$ per group.

Figure 6. Soybean oil diet alters the levels of oxylipin metabolites and endocannabinoids in conventionally raised and germ-free mice. Absolute levels of oxylipins (A), arachidonic acid (AA) (B) and endocannabinoids (C,D) measured in IECs from Conv and GF mice fed either Viv chow or SO+f diet for 8 weeks. ${ }^{a}$ vs Conv Viv , ${ }^{\mathrm{b}}$ vs Conv $\mathrm{SO}+\mathrm{f},{ }^{\mathrm{c}}$ vs GF Viv, $P<0.05$, oneway ANOVA, Tukey's post hoc. $P=0.07$ for AA. N=6 per group. 


\section{Diet High in Soybean Oil Increases Susceptibility to Colitis in Mice}

\section{Figure 7. Proposed model by which a diet high in soybean oil increases susceptibility to}

colitis. See text for details.

Funding Sources: National Institutes of Health R01 (DK053892 to F.M.S.); Crohn's Colitis Foundation Career Development Award (454808 to PD); UC Riverside Metabolomics Core Seed Grant (to F.M.S and P.D.); NIH/UC Davis WCMC Seed Grant (to J.B. and P.D.). National Institutes of Health NIGMS grant (R35GM124724 to A.H.)

\section{REFERENCES}

Adachi, M., Kurotani, R., Morimura, K., Shah, Y., Sanford, M., Madison, B.B., Gumucio, D.L., Marin, H.E., Peters, J.M., Young, H.A., et al. (2006). Peroxisome proliferator activated receptor gamma in colonic epithelial cells protects against experimental inflammatory bowel disease. Gut $55,1104-1113$.

Agrawal, K., Hassoun, L.A., Foolad, N., Pedersen, T.L., Sivamani, R.K., and Newman, J.W. (2017). Sweat lipid mediator profiling: a noninvasive approach for cutaneous research. J. Lipid Res. 58, 188-195.

Alam, M.T., Amos, G.C.A., Murphy, A.R.J., Murch, S., Wellington, E.M.H., and Arasaradnam, R.P. (2020). Microbial imbalance in inflammatory bowel disease patients at different taxonomic levels. Gut Pathog. 12, 1.

Alavi, S., Mitchell, J.D., Cho, J.Y., Liu, R., Macbeth, J.C., and Hsiao, A. (2020). Interpersonal Gut Microbiome Variation Drives Susceptibility and Resistance to Cholera Infection. Cell 181, 1533-1546.e13.

Alvheim, A.R., Torstensen, B.E., Lin, Y.H., Lillefosse, H.H., Lock, E.J., Madsen, L., Hibbeln, J.R., and Malde, M.K. (2013). Dietary linoleic acid elevates endogenous 2-arachidonoylglycerol and anandamide in Atlantic salmon (Salmo salar L.) and mice, and induces weight gain and inflammation in mice. Br. J. Nutr. 109, 1508-1517.

Barros, K.V., Xavier, R.A.N., Abreu, G.G., Martinez, C.A.R., Ribeiro, M.L., Gambero, A., Carvalho, P.O., Nascimento, C.M.O., and Silveira, V.L.F. (2010). Soybean and fish oil mixture increases IL-10, protects against DNA damage and decreases colonic inflammation in rats with dextran sulfate sodium (DSS) colitis. Lipids Health Dis. 9, 68.

Berg, D.J., Davidson, N., Kühn, R., Müller, W., Menon, S., Holland, G., Thompson-Snipes, L., Leach, M.W., and Rennick, D. (1996). Enterocolitis and colon cancer in interleukin-10-deficient mice are associated with aberrant cytokine production and CD4(+) TH1-like responses. J. Clin. Invest. 98, 1010-1020. 
Blasbalg, T.L., Hibbeln, J.R., Ramsden, C.E., Majchrzak, S.F., and Rawlings, R.R. (2011). Changes in consumption of omega-3 and omega-6 fatty acids in the United States during the 20th century. Am. J. Clin. Nutr. 93, 950-962.

Briancon, N., and Weiss, M.C. (2006). In vivo role of the HNF4alpha AF-1 activation domain revealed by exon swapping. EMBO J. 25, 1253-1262.

Buttó, L.F., and Haller, D. (2016). Dysbiosis in intestinal inflammation: Cause or consequence. Int. J. Med. Microbiol. 306, 302-309.

Calder, P.C. (2005). Polyunsaturated fatty acids and inflammation. Biochem. Soc. Trans. 33, 423-427.

Cani, P.D., Plovier, H., Van Hul, M., Geurts, L., Delzenne, N.M., Druart, C., and Everard, A. (2016). Endocannabinoids - at the crossroads between the gut microbiota and host metabolism. Nature Reviews Endocrinology 12, 133-143.

Chapkin, R.S., Davidson, L.A., Ly, L., Weeks, B.R., Lupton, J.R., and McMurray, D.N. (2007). Immunomodulatory effects of (n-3) fatty acids: putative link to inflammation and colon cancer. J. Nutr. 137, 200S - 204S.

Chellappa, K., Deol, P., Evans, J.R., Vuong, L.M., Chen, G., Briançon, N., Bolotin, E., Lytle, C., Nair, M.G., and Sladek, F.M. (2016). Opposing roles of nuclear receptor HNF4 $\alpha$ isoforms in colitis and colitis-associated colon cancer. Elife 5.

Chen, W.S., Manova, K., Weinstein, D.C., Duncan, S.A., Plump, A.S., Prezioso, V.R., Bachvarova, R.F., and Darnell, J.E., Jr (1994). Disruption of the HNF-4 gene, expressed in visceral endoderm, leads to cell death in embryonic ectoderm and impaired gastrulation of mouse embryos. Genes Dev. 8, 2466-2477.

Couter, C.J., and Surana, N.K. (2016). Isolation and Flow Cytometric Characterization of Murine Small Intestinal Lymphocytes. J. Vis. Exp.

Darfeuille-Michaud, A., Boudeau, J., Bulois, P., Neut, C., Glasser, A.-L., Barnich, N., Bringer, M.-A., Swidsinski, A., Beaugerie, L., and Colombel, J.-F. (2004). High prevalence of adherentinvasive Escherichia coli associated with ileal mucosa in Crohn's disease. Gastroenterology 127, 412-421.

Davison, J.M., Lickwar, C.R., Song, L., Breton, G., Crawford, G.E., and Rawls, J.F. (2017). Microbiota regulate intestinal epithelial gene expression by suppressing the transcription factor Hepatocyte nuclear factor 4 alpha. Genome Res.

Deol, P., Evans, J.R., Dhahbi, J., Chellappa, K., Han, D.S., Spindler, S., and Sladek, F.M. (2015). Soybean oil is more obesogenic and diabetogenic than coconut oil and fructose in mouse: potential role for the liver. PLoS One 10, e0132672.

Deol, P., Fahrmann, J., Yang, J., Evans, J.R., Rizo, A., Grapov, D., Salemi, M., Wanichthanarak, K., Fiehn, O., Phinney, B., et al. (2017). Omega-6 and omega-3 oxylipins are implicated in 
soybean oil-induced obesity in mice. Sci. Rep. 7, 12488.

Diab, J., Al-Mahdi, R., Gouveia-Figueira, S., Hansen, T., Jensen, E., Goll, R., Moritz, T., Florholmen, J., and Forsdahl, G. (2019). A Quantitative Analysis of Colonic Mucosal Oxylipins and Endocannabinoids in Treatment-Naïve and Deep Remission Ulcerative Colitis Patients and the Potential Link With Cytokine Gene Expression. Inflammatory Bowel Diseases 25, 490-497.

Ellulu, M.S., Patimah, I., Khaza'ai, H., Rahmat, A., and Abed, Y. (2017). Obesity and inflammation: the linking mechanism and the complications. Arch. Med. Sci. 13, 851-863.

Gabbs, M., Leng, S., Devassy, J.G., Monirujjaman, M., and Aukema, H.M. (2015). Advances in Our Understanding of Oxylipins Derived from Dietary PUFAs. Adv. Nutr. 6, 513-540.

Gkouskou, K.K., Deligianni, C., Tsatsanis, C., and Eliopoulos, A.G. (2014). The gut microbiota in mouse models of inflammatory bowel disease. Front. Cell. Infect. Microbiol. 4, 28.

Hernández-Chirlaque, C., Aranda, C.J., Ocón, B., Capitán-Cañadas, F., Ortega-González, M., Carrero, J.J., Suárez, M.D., Zarzuelo, A., Sánchez de Medina, F., and Martínez-Augustin, O. (2016). Germ-free and Antibiotic-treated Mice are Highly Susceptible to Epithelial Injury in DSS Colitis. J. Crohns. Colitis 10, 1324-1335.

Hintze, K.J., Benninghoff, A.D., Cho, C.E., and Ward, R.E. (2018). Modeling the Western Diet for Preclinical Investigations. Adv. Nutr. 9, 263-271.

Kaur, N., Chen, C.-C., Luther, J., and Kao, J.Y. (2011). Intestinal dysbiosis in inflammatory bowel disease. Gut Microbes 2, 211-216.

Knight-Sepulveda, K., Kais, S., Santaolalla, R., and Abreu, M.T. (2015). Diet and Inflammatory Bowel Disease. Gastroenterol. Hepatol. 11, 511-520.

Ko, H.L., Zhuo, Z., and Ren, E.C. (2019). HNF4 $\alpha$ Combinatorial Isoform Heterodimers Activate Distinct Gene Targets that Differ from Their Corresponding Homodimers. Cell Rep. 26, 25492557.e3.

Kühn, R., Löhler, J., Rennick, D., Rajewsky, K., and Müller, W. (1993). Interleukin-10-deficient mice develop chronic enterocolitis. Cell 75, 263-274.

Lee, J.W., Bajwa, P.J., Carson, M.J., Jeske, D.R., Cong, Y., Elson, C.O., Lytle, C., and Straus, D.S. (2007). Fenofibrate Represses Interleukin-17 and Interferon- $\gamma$ Expression and Improves Colitis in Interleukin-10-Deficient Mice. Gastroenterology 133, 108-123.

Lee, S.H., Kwon, J.E., and Cho, M.-L. (2018). Immunological pathogenesis of inflammatory bowel disease. Intest Res 16, 26-42.

Maeda, Y., Hwang-Verslues, W.W., Wei, G., Fukazawa, T., Durbin, M.L., Owen, L.B., Liu, X., and Sladek, F.M. (2006). Tumour suppressor p53 down-regulates the expression of the human hepatocyte nuclear factor $4 \alpha$ (HNF4 $\alpha)$ gene. Biochem. J 400, 303-313. 
Marion-Letellier, R., Savoye, G., and Ghosh, S. (2016). IBD: In Food We Trust. J. Crohns. Colitis 10, 1351-1361.

Martinez-Medina, M., Denizot, J., Dreux, N., Robin, F., Billard, E., Bonnet, R., DarfeuilleMichaud, A., and Barnich, N. (2014). Western diet induces dysbiosis with increased E coli in CEABAC10 mice, alters host barrier function favouring AIEC colonisation. Gut 63, 116-124.

Martini, E., Krug, S.M., Siegmund, B., Neurath, M.F., and Becker, C. (2017). Mend Your Fences: The Epithelial Barrier and its Relationship With Mucosal Immunity in Inflammatory Bowel Disease. Cell Mol Gastroenterol Hepatol 4, 33-46.

Marton, L.T., Goulart, R. de A., Carvalho, A.C.A. de, and Barbalho, S.M. (2019). Omega Fatty Acids and Inflammatory Bowel Diseases: An Overview. Int. J. Mol. Sci. 20.

Moldal, T., Løkka, G., Wiik-Nielsen, J., Austbø, L., Torstensen, B.E., Rosenlund, G., Dale, O.B., Kaldhusdal, M., and Koppang, E.O. (2014). Substitution of dietary fish oil with plant oils is associated with shortened mid intestinal folds in Atlantic salmon (Salmo salar). BMC Vet. Res. 10,60 .

Molodecky, N.A., Soon, I.S., Rabi, D.M., Ghali, W.A., Ferris, M., Chernoff, G., Benchimol, E.I., Panaccione, R., Ghosh, S., Barkema, H.W., et al. (2012). Increasing incidence and prevalence of the inflammatory bowel diseases with time, based on systematic review. Gastroenterology 142, 46-54 e42; quiz e30.

Ohno, H. (2015). Impact of commensal microbiota on the host pathophysiology: focusing on immunity and inflammation. Seminars in Immunopathology 37, 1-3.

Palmela, C., Chevarin, C., Xu, Z., Torres, J., Sevrin, G., Hirten, R., Barnich, N., Ng, S.C., and Colombel, J.-F. (2018). Adherent-invasive Escherichia coli in inflammatory bowel disease. Gut 67, 574-587.

Ramstedt, U., Serhan, C.N., Lundberg, U., Wigzell, H., and Samuelsson, B. (1984). Inhibition of human natural killer cell activity by $(14 \mathrm{R}, 15 \mathrm{~S})-14,15$-dihydroxy-5Z,8Z,10E,12E- icosatetraenoic acid. Proc. Natl. Acad. Sci. U. S. A. 81, 6914-6918.

Rashvand, S., Somi, M.H., Rashidkhani, B., and Hekmatdoost, A. (2015). Dietary fatty acid intakes are related to the risk of ulcerative colitis: a case-control study. Int. J. Colorectal Dis. 30, $1255-1260$.

Redlich, S., Ribes, S., Schütze, S., and Nau, R. (2014). Palmitoylethanolamide stimulates phagocytosis of Escherichia coli K1 by macrophages and increases the resistance of mice against infections. J. Neuroinflammation 11, 108.

Schroeder, B.O. (2019). Fight them or feed them: how the intestinal mucus layer manages the gut microbiota. Gastroenterol. Rep. 7, 3-12.

Shawki, A., Ramirez, R., Spalinger, M.R., Ruegger, P.M., Sayoc-Becerra, A., Santos, A.N., Chatterjee, P., Canale, V., Mitchell, J.D., Macbeth, J.C., et al. (2020). The autoimmune 


\section{Diet High in Soybean Oil Increases Susceptibility to Colitis in Mice}

susceptibility gene, PTPN2, restricts expansion of a novel mouse adherent-invasive E. coli. Gut Microbes 11, 1547-1566.

Sladek, F.M., Zhong, W.M., Lai, E., and Darnell, J.E., Jr. (1990). Liver-enriched transcription factor HNF-4 is a novel member of the steroid hormone receptor superfamily. Genes Dev. 4, $2353-2365$.

Sommer, F., and Backhed, F. (2013). The gut microbiota--masters of host development and physiology. Nat. Rev. Microbiol. 11, 227-238.

Tamboli, C.P., Neut, C., Desreumaux, P., and Colombel, J.F. (2004). Dysbiosis in inflammatory bowel disease. Gut 53, 1-4.

Tjonneland, A., Olsen, A., Overvad, K., Bergmann, M.M., Boeing, H., Nagel, G., Linseisen, J., Hallmans, G., Palmqvist, R., Sjodin, H., et al. (2009). IBD in EPIC Study Investigators: Linoleic acid, a dietary n-6 polyunsaturated fatty acid, and the aetiology of ulcerative colitis: a nested case-control study within a European prospective cohort study. Gut 58, 1606-1611.

UK IBD Genetics Consortium, Barrett, J.C., Lee, J.C., Lees, C.W., Prescott, N.J., Anderson, C.A., Phillips, A., Wesley, E., Parnell, K., Zhang, H., et al. (2009). Genome-wide association study of ulcerative colitis identifies three new susceptibility loci, including the HNF4A region. Nat. Genet. 41, 1330-1334.

USDA Economic Research Service (2020). Oil Crops Yearbook.

Wiese, D.M., Horst, S.N., Brown, C.T., Allaman, M.M., Hodges, M.E., Slaughter, J.C., Druce, J.P., Beaulieu, D.B., Schwartz, D.A., Wilson, K.T., et al. (2016). Serum Fatty Acids Are Correlated with Inflammatory Cytokines in Ulcerative Colitis. PLoS One 11, e0156387.

Wood, N.J. (2010). IBD: High dietary intake of linoleic acid more than doubles the risk of ulcerative colitis. Nat. Rev. Gastroenterol. Hepatol. 7, 65.

Yuan, X., Ta, T.C., Lin, M., Evans, J.R., Dong, Y., Bolotin, E., Sherman, M.A., Forman, B.M., and Sladek, F.M. (2009). Identification of an endogenous ligand bound to a native orphan nuclear receptor. PLoS One 4, e5609.

Zhang, W., Li, H., Dong, H., Liao, J., Hammock, B.D., and Yang, G.-Y. (2013). Soluble epoxide hydrolase deficiency inhibits dextran sulfate sodium-induced colitis and carcinogenesis in mice. Anticancer Res. 33, 5261-5271. 
A

Hnf4a
B

Body weight

Body weight at harvest

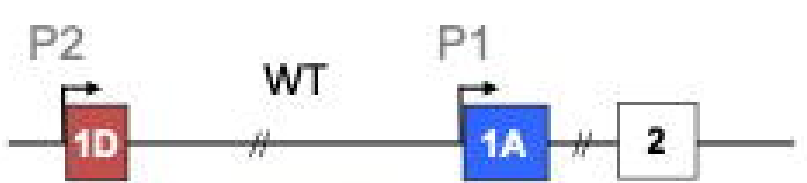

\section{P2 $\quad \alpha 1 \mathrm{HMZ} \quad \mathrm{P} 1$}

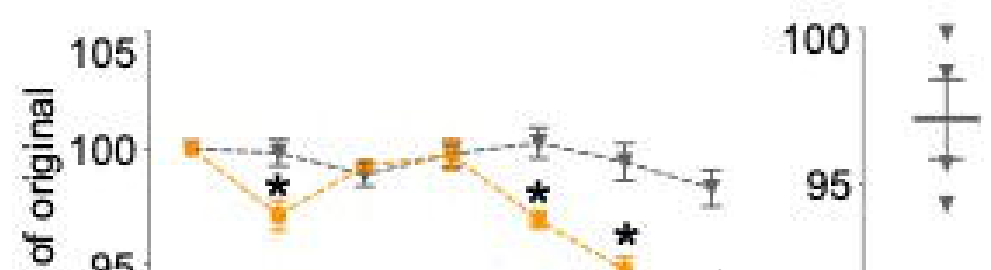

version? 95 sted February 10, 2021. The copyright holder for this preprint
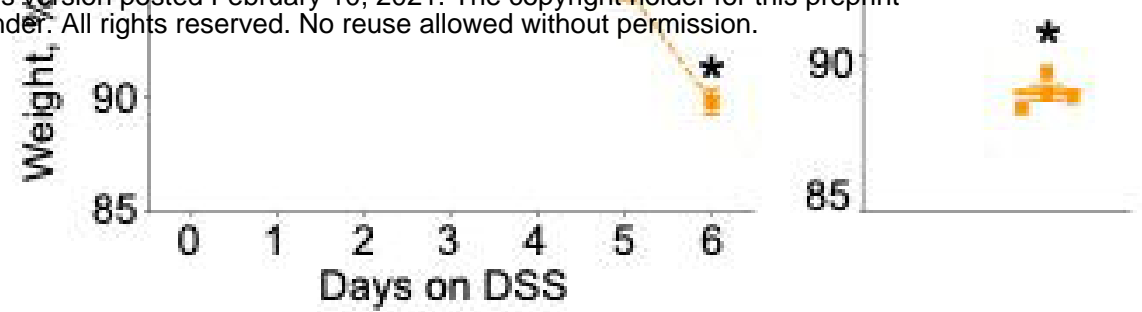

$\nabla \alpha 1$ Viv

$\alpha 1 \mathrm{SO}+\mathrm{f}$

\section{C}

$\alpha 1 \mathrm{HMZ}$ Viv

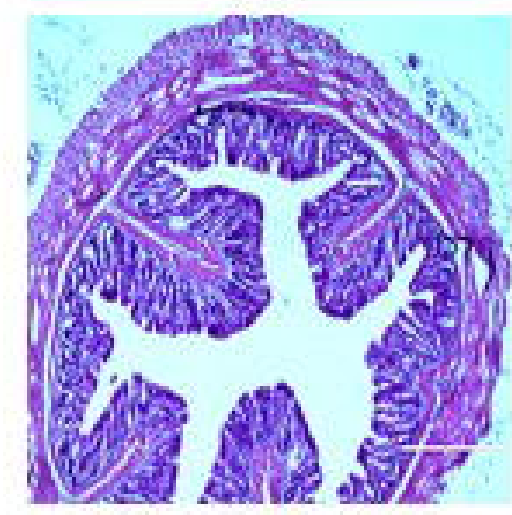

$\alpha 1 \mathrm{HMZ} \mathrm{SO}+\mathrm{f}$

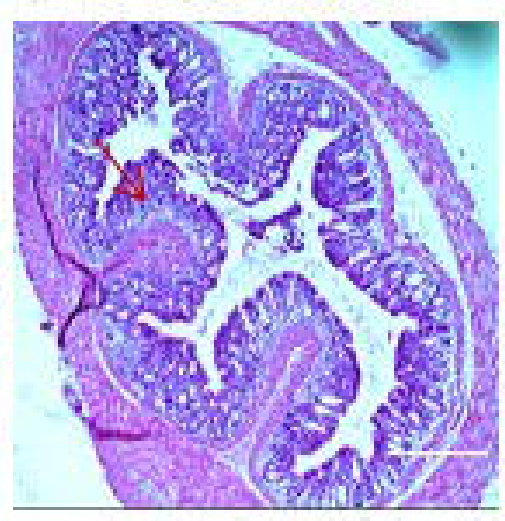

Colon Length

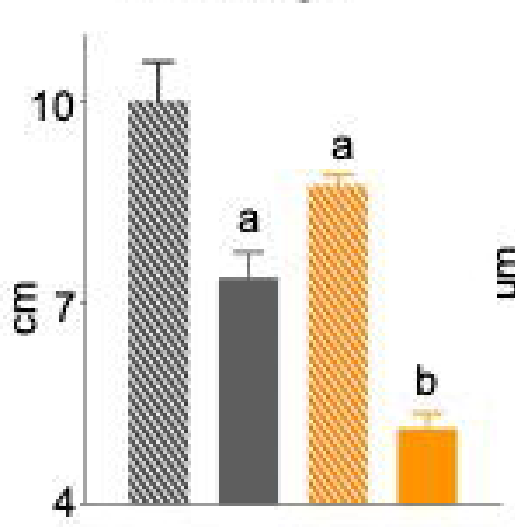

Nintreated $\alpha 1$ Viv

Crypt Length

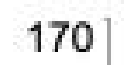

DSS-treated $\alpha 1$ Viv

N Untreated $\alpha 1$ SO+f

DSS-treated $\alpha 1$ SO+f

D

Immune Cell Analysis

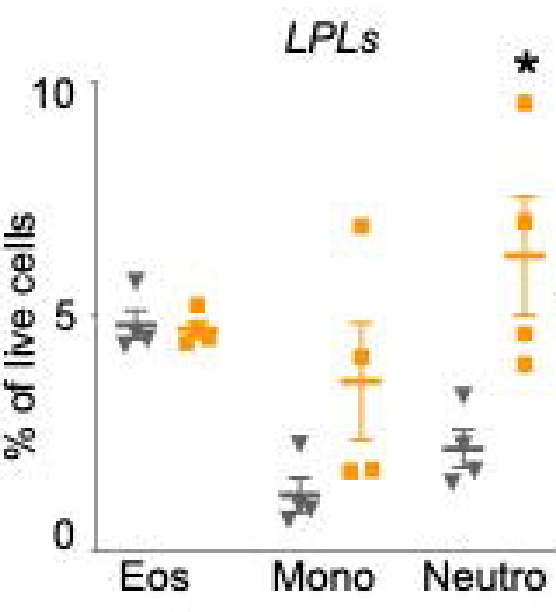

$\mathrm{F}$

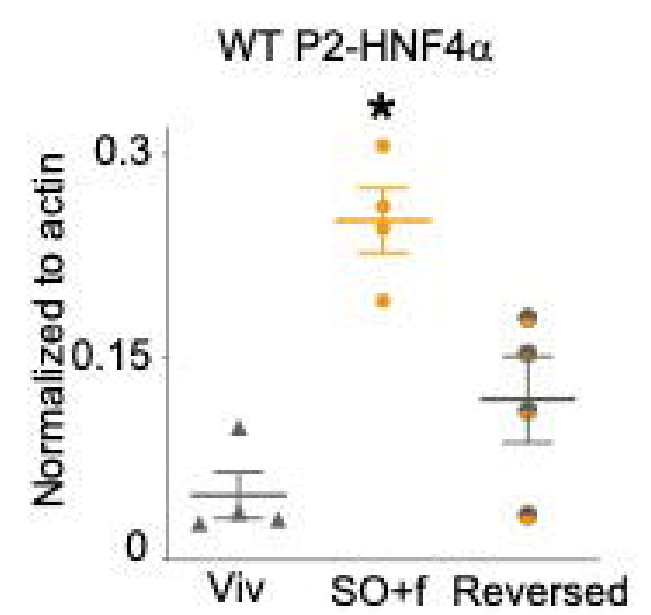

IELS

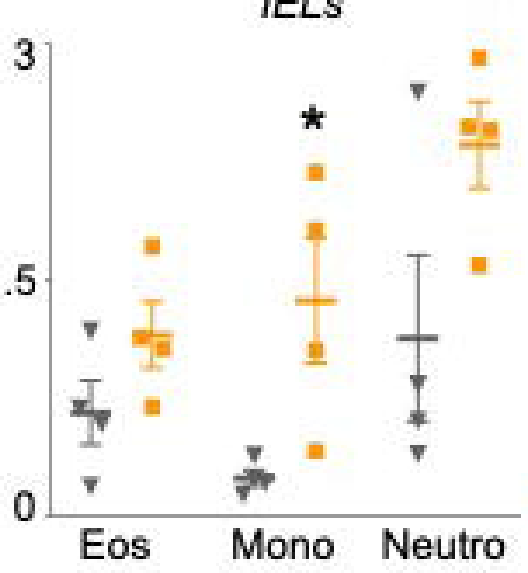

E

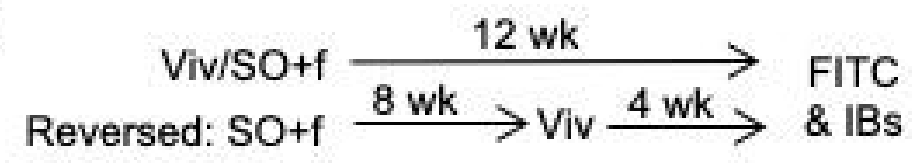

WT

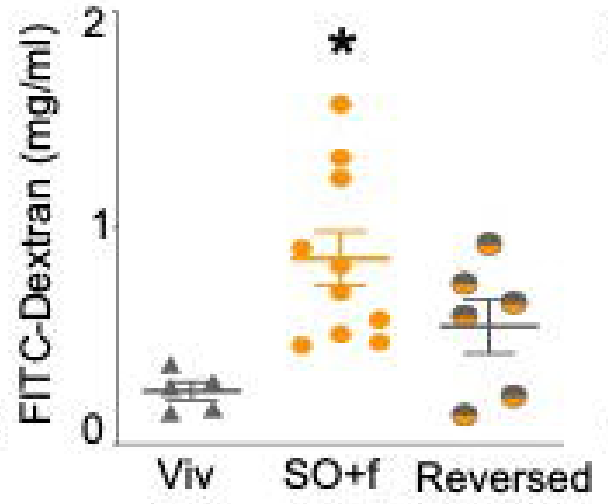

$\alpha 1 \mathrm{HMZ}$

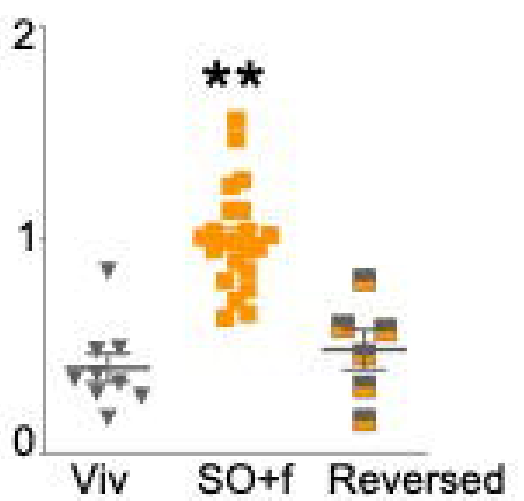

WT P1-HNF4 $\alpha$

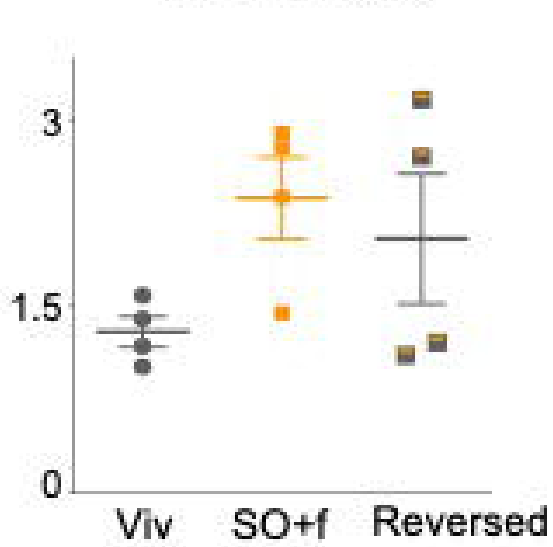

$\triangle$ WT Viv

- WT SO+f

- WT Reversed: SO+f to VIV $\nabla \alpha 1 \mathrm{Viv}$

$\alpha 1 \mathrm{SO}+\mathrm{f}$

$\alpha 1$ Reversed: SO+f to Viv 
Figure 3

A Bacterial Species - IECs

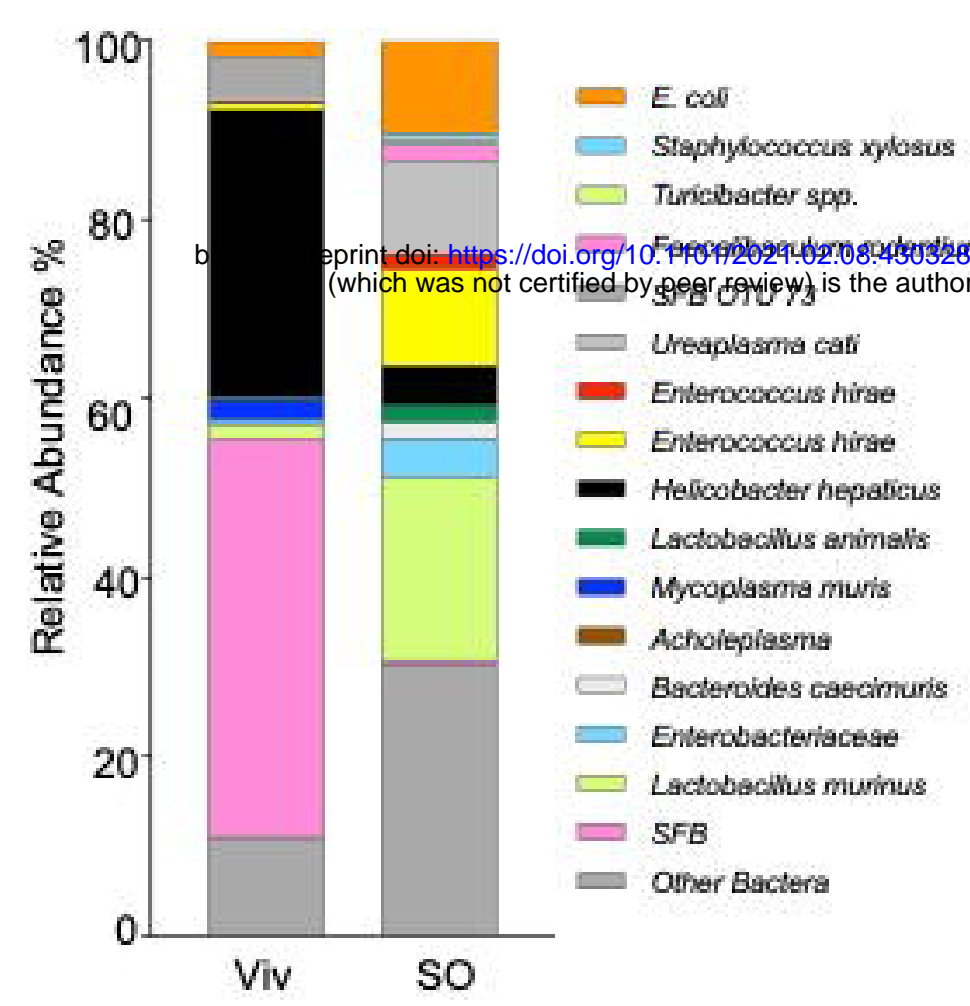

B

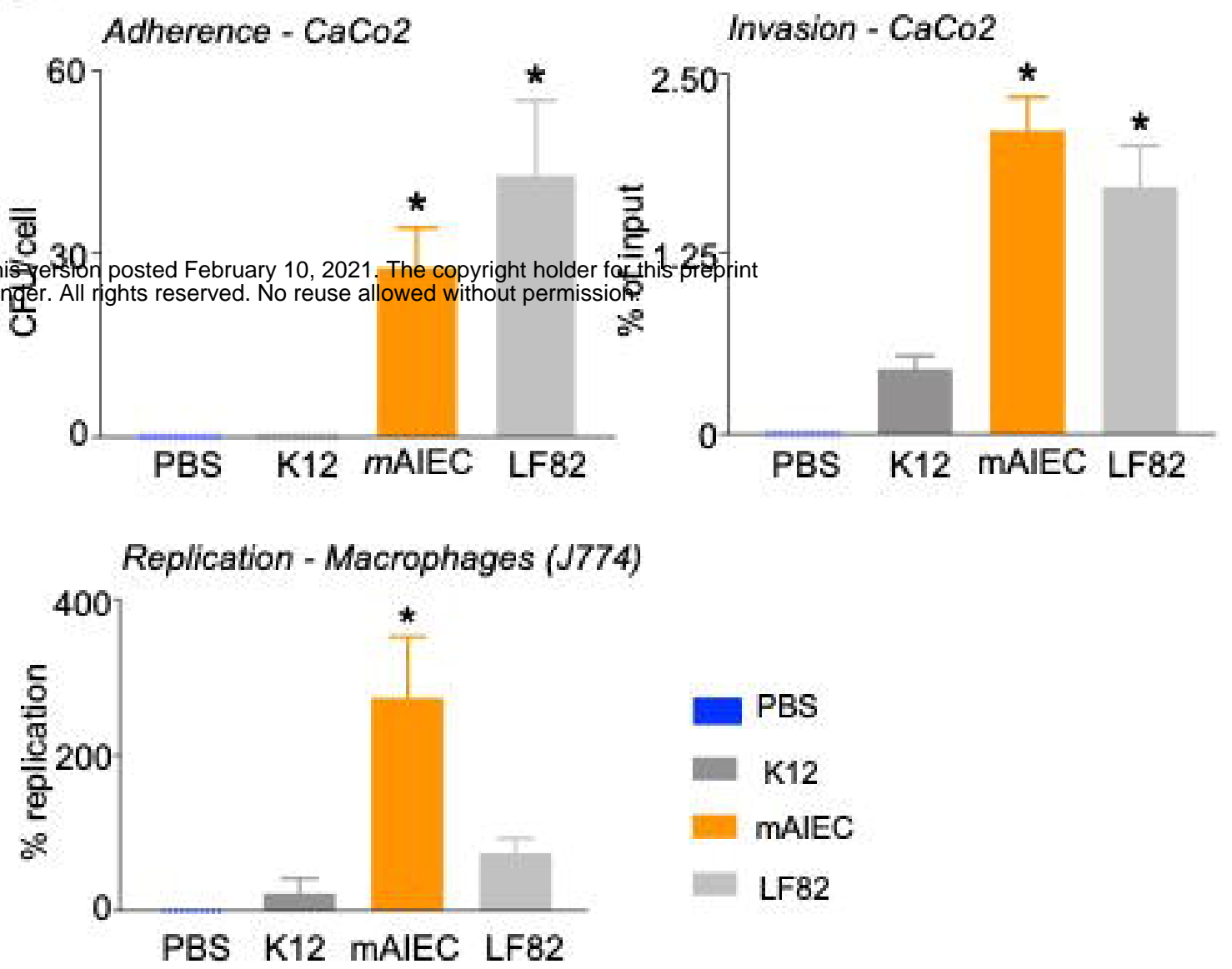

C
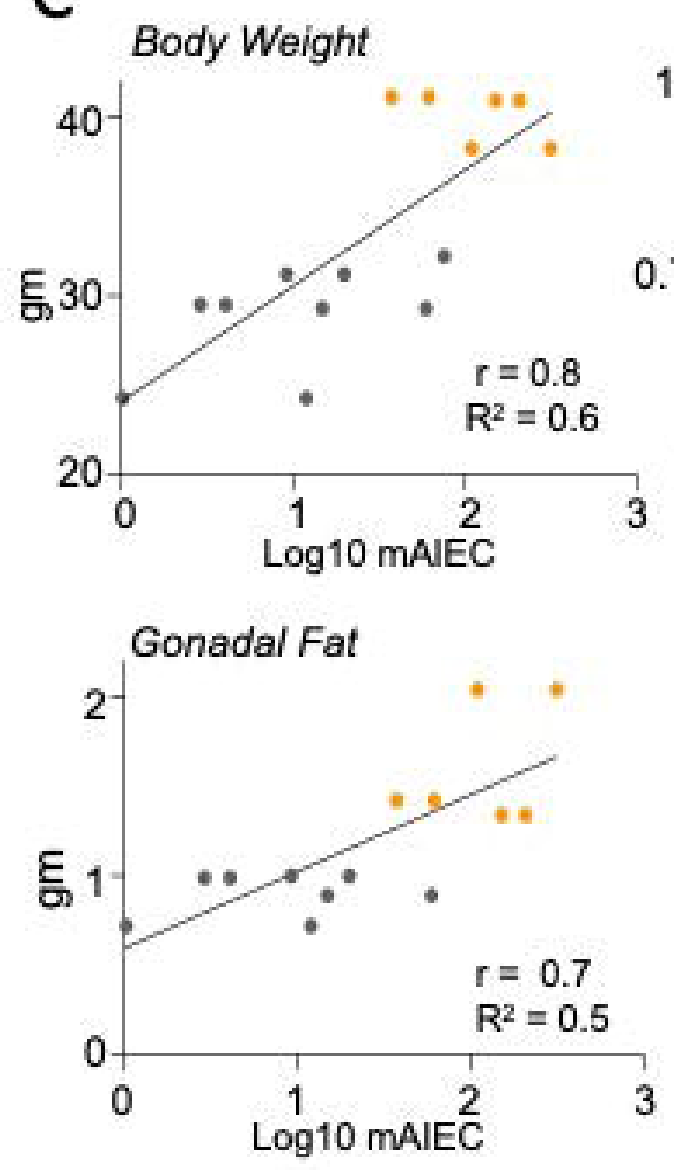
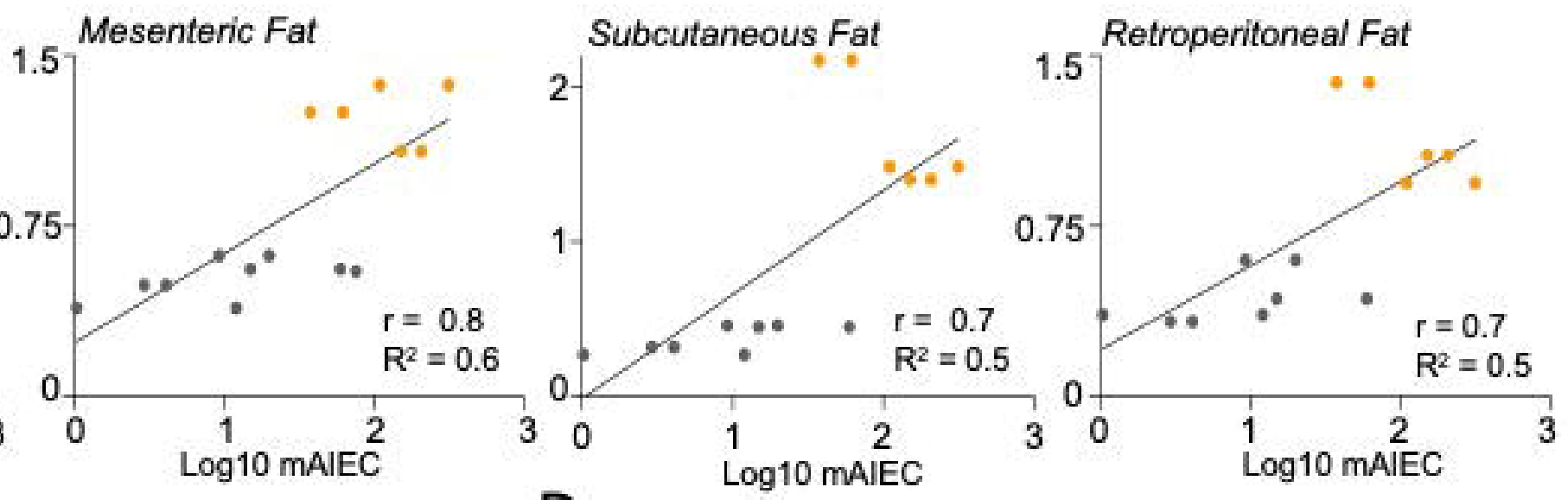
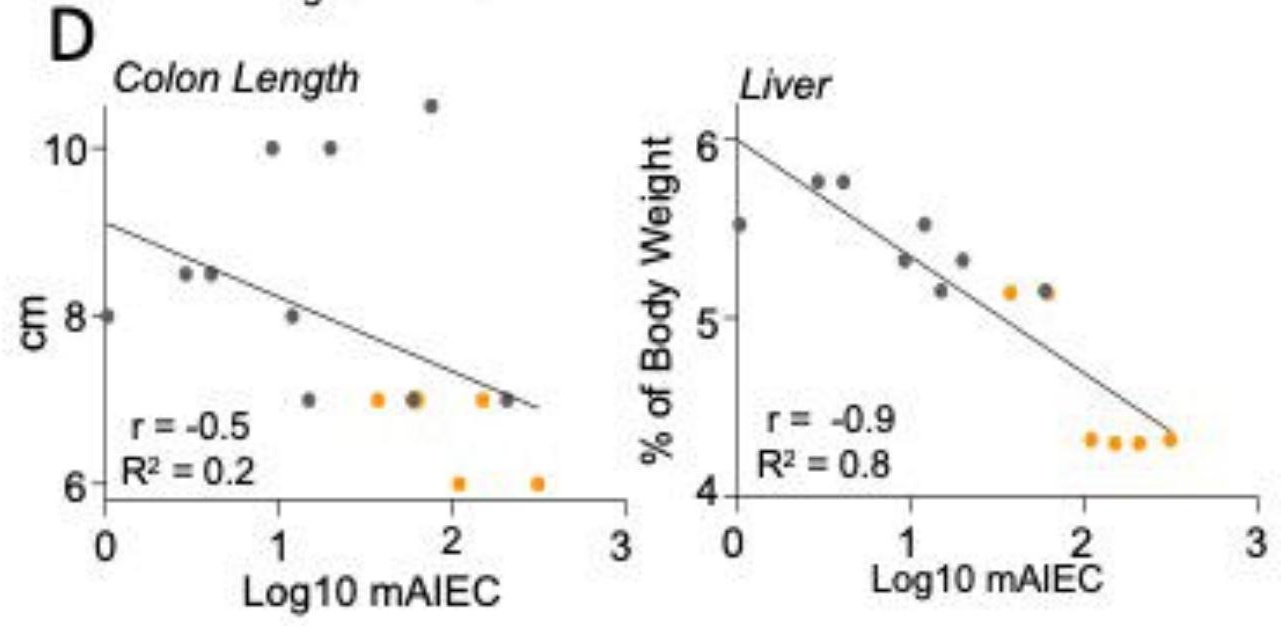
A
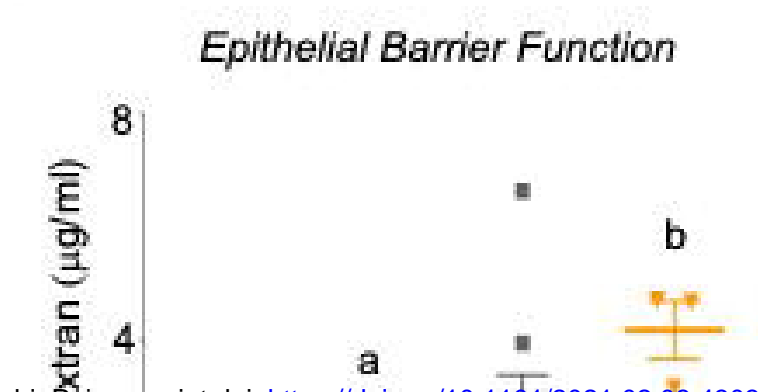

bioluxiv preprint doi: https://doi.org/10.1101/2021.02.08.430328; this version-postedfebruary 10

All nots Yesenved

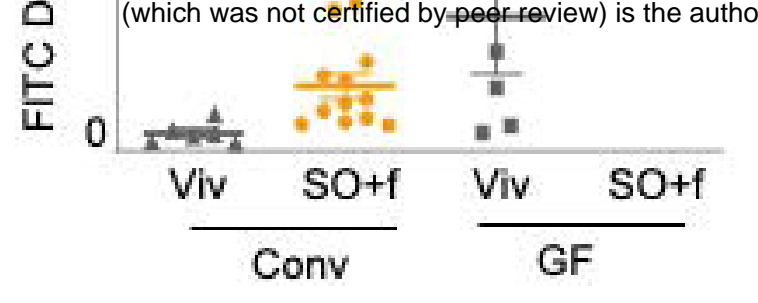

B

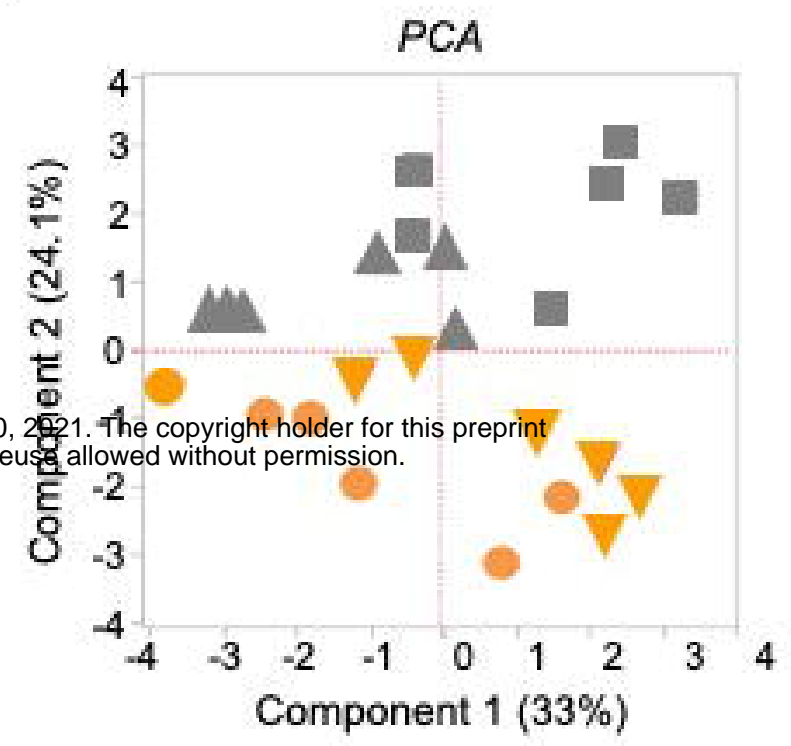

C

$$
\begin{gathered}
\text { Conv } \\
(\text { Viv and SO+f) }
\end{gathered}
$$

Dysregulated by diet:<smiles>[13CH][13CH]</smiles>

Dysregulated by microbiome:

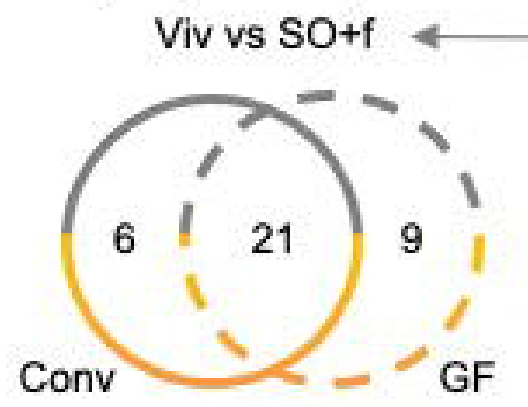
IEC Metabolomics $\longrightarrow$ GF vs Conv

Dysregulated by diet and microbiome

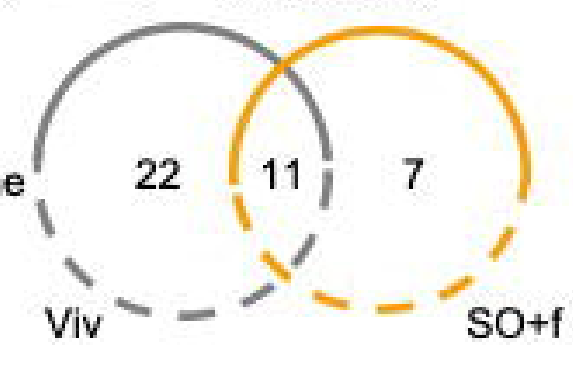

D

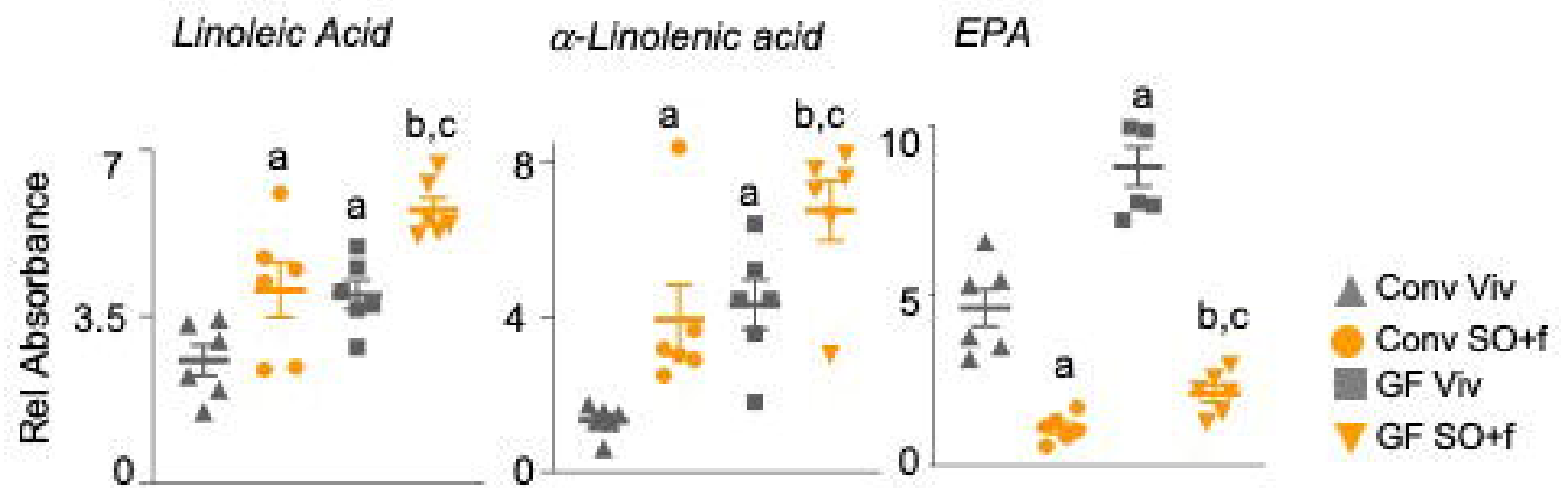


Figure 7

bioRxiv preprint doi: https://doi.org/10.1101/2021.02.08.430328; this version posted February 10, 2021. The copyright holder for this preprint (which was not certified by peer review) is the author/funder. All rights reserved. No reuse allowed without permission.

\section{Soybean oil diet}

Omega-6 LA Omega-3 ALA

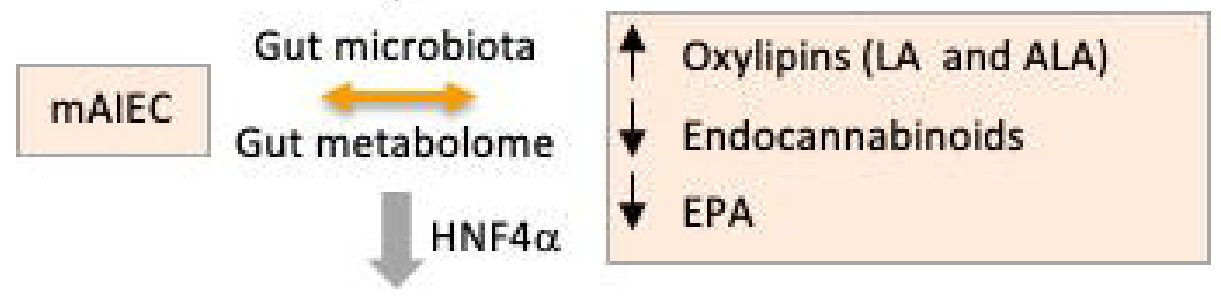

Barrier dysfunction

Colitis 